\title{
Article
}

\section{Capturing a Space Target Using a Flexible Space Robot}

\author{
Xiao-Feng Liu ${ }^{1,2} \oplus^{\oplus}$, Xiao-Yu Zhang ${ }^{1,2}{ }^{\oplus}$, Guo-Ping Cai ${ }^{1,2, *}$ and Wu-Jun Chen ${ }^{1,2}$ \\ 1 Key Laboratory of Hydrodynamics of Ministry of Education, School of Naval Architecture, Ocean \& Civil \\ Engineering, Shanghai Jiaotong University, Shanghai 200240, China; peterliuxiaofeng@sjtu.edu.cn (X.-F.L.); \\ 568412488@sjtu.edu.cn (X.-Y.Z.); cwj@sjtu.edu.cn (W.-J.C.) \\ 2 State Key Laboratory of Ocean Engineering, Shanghai Jiaotong University, Shanghai 200240, China \\ * Correspondence: caigp@sjtu.edu.cn
}

\section{check for}

updates

Citation: Liu, X.-F.; Zhang, X.-Y.; Cai, G.-P.; Chen, W.-J. Capturing a Space Target Using a Flexible Space Robot. Appl. Sci. 2022, 12, 984. https:// doi.org/10.3390/app12030984

Academic Editor: Shuaishuai Sun

Received: 22 November 2021

Accepted: 27 December 2021

Published: 19 January 2022

Publisher's Note: MDPI stays neutral with regard to jurisdictional claims in published maps and institutional affiliations.

Copyright: () 2022 by the authors Licensee MDPI, Basel, Switzerland. This article is an open access article distributed under the terms and conditions of the Creative Commons Attribution (CC BY) license (https:/ / creativecommons.org/licenses/by/ $4.0 /)$.

\begin{abstract}
Capturing space targets by space robots is significant for on-orbit service and is a challenging research topic nowadays. This paper focuses on the dynamics and control of capturing a non-cooperative space target by a space robot with a long flexible manipulator. Firstly, the dynamic equation of the flexible space robot is given. The Hertz contact model is used to describe the contact force between the robot and the target. Secondly, an active compliance controller is designed to reduce the capture impact on the robot. Finally, the capture impact on the whole system is analyzed in detail in four scenarios: the combination of two kinds of movement forms and two kinds of relative positions of the robot and the target before capturing. Simulation results indicate that the capturing operation may cause complicated dynamic behaviors such as the vibration of elastic links and the continuous collision of the target. Moreover, the results show that the control method effectively offsets the capture impact on the space robot system. In general, this work lays a theoretical foundation for further study of the dynamic phenomena of the capture process.
\end{abstract}

Keywords: flexible space robot; space target; capture; impact; control

\section{Introduction}

With the development of science and technology, human explorations of space have been growing quickly. A number of space launches have been carried out in recent years to meet the demands of communication, weather monitoring, and the military. However, human space exploration activities have tremendously affected the space environment, leaving a large amount of space debris such as failure satellites, upper rocket stages, and collision derivatives, which bring a significant threat to human space activities. To ensure the security of spacecrafts, some active debris removal (ADR) schemes were proposed, such as lowering the orbit of near-earth target debris and burning them down in the atmosphere, lifting the debris on the geostationary Earth orbit to a graveyard orbit. In all of these schemes, capturing space debris on-orbit is necessary. Since most space debris are noncooperative and information about them, for instance, mass, centroid location, geometric shape, and motion state, is unknown, the capturing operation is a difficult task to realize.

To date, some capture methods have already been proposed, such as manipulator, net, and hook. Among them, the research of manipulator-based capturing technology is a significant direction [1,2]. Related works include those of McDonald Dettwiler Space and Advanced Robotics Ltd. (MDSAR) who developed a simulation tool to analyze the dynamic behavior between robot and target during contact [3]. Wee and Walker [4] studied the contact between a free-flying space robot and a non-cooperative target. They developed an algorithm to minimize the contact impulse by planning the robot trajectory tracking and impulse minimization. In Cyril and Jaar's research [5,6], post-capture dynamics of a flexible spacecraft manipulator were studied deeply. Yoshida et al. [7-12] carried out extensive studies on the operation of capturing a free-flying/free-floating object by a rigid space robot, including impact dynamics modeling, impulse minimizing, and impedance control. Shibli 
and $\mathrm{Su}[13,14]$ studied the dynamic modeling and control of the capture of a satellite by a rigid space robot. To reduce the difficulty of the capturing operation, Matunaga et al. [15] proposed a contact/push-based control method for reducing the angular momentum of an uncontrolled target satellite. For the same reason, Uyama and Nakanishi [16,17] utilized a controllable compliant wrist installed on a rigid robot to offset the impact of the target satellite. Thai et al. [18] used a Magneto-Rheological (MR) damper to offset the impact from the target satellite too. $\mathrm{Xu}$ et al. $[19,20]$ studied the captures of a non-cooperative object and a larger flexible spacecraft by a rigid space robot, respectively. Liu et al. [21] and $\mathrm{Yu}$ et al. [22] conducted a series of studies on the dynamics and control of capturing a floating rigid body by a rigid space robot. Nishida et al. [23-26] studied the dynamics of capturing space debris by a rigid space robot, and some research results about capturing strategy were achieved. Liu et al. [27], Liu et al. [28,29], and Stolfi et al. [30,31] studied the control problem of the capture of a larger tumbling object by multi rigid robot arms. Zarafshan et al. [32,33] studied the control problem of cooperative object manipulation by a rigid-flexible arm. From the studies above, we can see that the capture of space objects using space robots has gained much attention, and there are many research results. However, there still are some problems remaining for further study. For example, in most existing studies, the capture missions are conducted by a rigid space robot. The flexible space robot has a longer manipulator, so the flexible space robot has a larger working space than the rigid space robot. Thus, a flexible space robot could finish the capture mission in a relatively safe position. However, the flexibility brought by the longer manipulator will cause more complex dynamics behaviors of the system during capturing. Such behaviors could make the capture a failure. To date, the research on the capturing operations realized by flexible space robots is insufficient but essential [1]. Therefore, it is essential and meaningful to research the dynamics and control of capturing a non-cooperative target by a flexible space robot.

In this paper, Jourdain's velocity variation principle is adopted to build the dynamics of a flexible space robot, and the Hertz contact theory is used to describe the contact force between the end-effecters of the manipulator and the target. Moreover, an active controller is designed to reduce the capture impact on the robot system. In the numerical simulation section, we analyze the complex dynamic behaviors in the capture process. Meanwhile, this section verifies the validity of the controller. This paper is organized as follows. Section 2 briefly presents the expression of the dynamic model of the flexible space robot. The contact model between the robot and the captured object is presented in Section 3. Section 4 provides the controller design process. Section 5 provides numerical simulations. Finally, Section 6 gives a concluding remark.

\section{Dynamic Model of Space Robot}

This paper uses a simplified flexible space robot and a target (shown in Figure 1) to study capturing operation. The space robot is composed of a spacecraft base (the body $B_{1}$ ), a manipulator (the bodies $B_{2}-B_{5}$ ), and an end effecter (the bodies $B_{6}$ and $B_{7}$ ). The manipulator consists of two flexible links (the bodies $B_{2}$ and $B_{3}$ ) and two rigid links (the bodies $B_{4}$ and $B_{5}$ ) and has six degrees of freedom (Axes 1-6). The body $B_{2}$ can rotate around Axes 1 and $2, B_{3}$ around Axis $3, B_{4}$ around Axis 4 , and the body $B_{5}$ around Axes 5 and 6 . The end effecter is composed of three same cylinder-shaped hands, two of which form $B_{6}$, while the other one forms $B_{7}$. The body $B_{8}$ is the space target to capture, denoted by a rigid cylinder that simulates the handle of a captured spacecraft. The space robot shown in Figure $1 \mathrm{a}$ is like the Shuttle Remote Manipulator System (SRMS) designed by the Canadian Space Agency (CSA).

Based on the Jourdain's velocity variation principle, the dynamic equation of the robot system can be expressed as [34] 


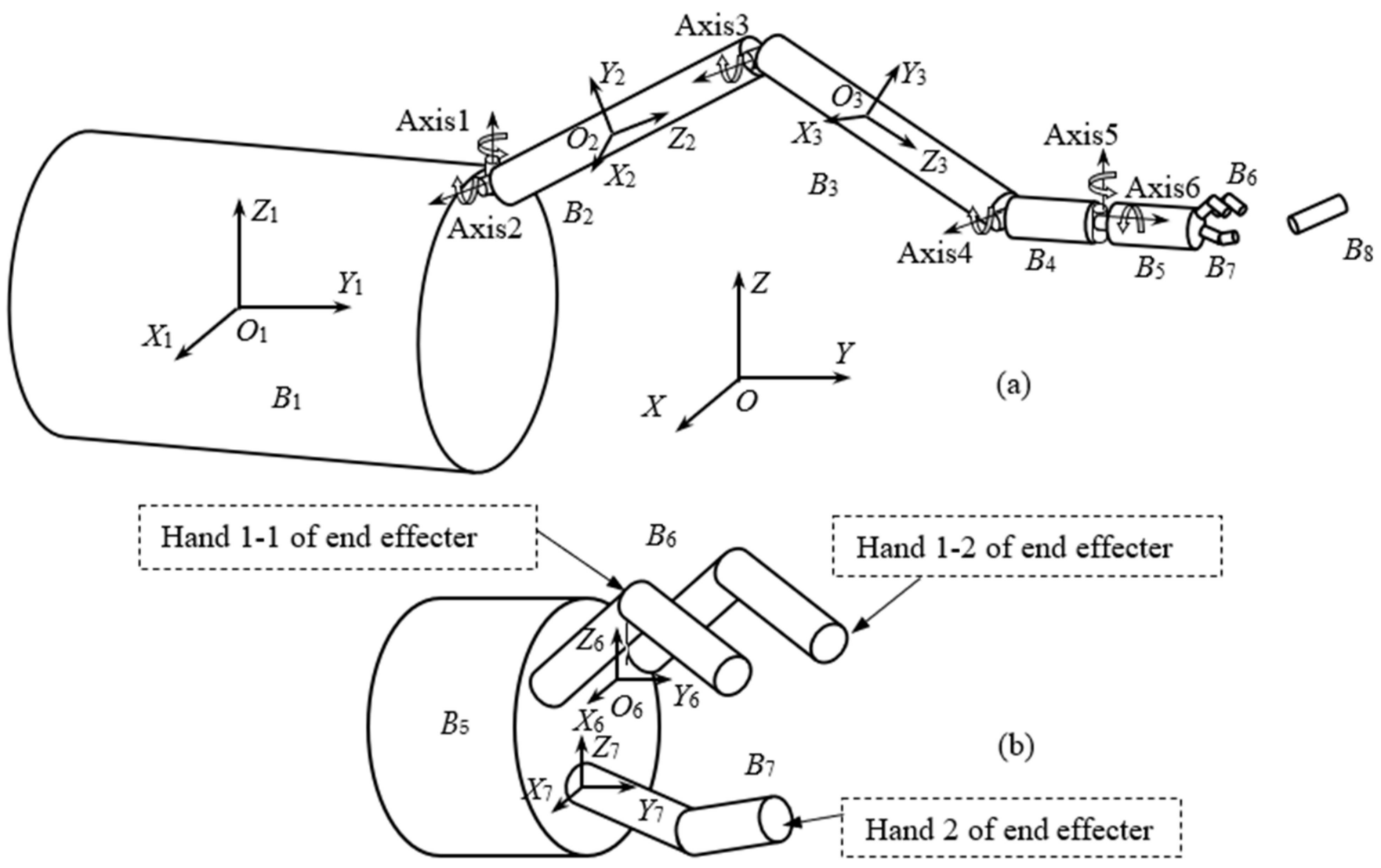

Figure 1. Space robot and the object to be captured: (a) the total diagram of the robot system, and (b) enlarged drawing of the end effecter.

$$
\sum_{i=1}^{n} \Delta \boldsymbol{v}_{i}^{\mathrm{T}}\left(-\boldsymbol{M}_{i} \dot{\boldsymbol{v}}_{i}-f_{i}^{\omega}-f_{i}^{u}+f_{i}^{o}\right)+\Delta P=0
$$

where $\boldsymbol{v}_{i}$ is the vector of configuration velocity of the $i$-th body, $\boldsymbol{M}_{i} \dot{\boldsymbol{v}}_{i}$ denotes the accelerationdependent inertia force acting on the $i$-th body, $f_{i}^{\omega}$ is the velocity-dependent inertia force acting on the $i$-th body, $f_{i}^{o}$ is the external force of the system acting on the $i$-th body, $f_{i}^{u}$ is the elastic force acting on the $i$-th body (if the $i$-th body is a rigid body, $f_{i}^{u}$ will be a zero vector), and $\Delta P$ is the sum of virtual power of the inner forces of the system. $n=7$ in Equation (1) since the robot system shown in Figure 1 is composed of seven bodies.

By the assumed mode method, the elastic force $f_{i}^{u}$ can be expressed as [34].

$$
f_{i}^{u}=\left[\begin{array}{lll}
0^{\mathrm{T}} & 0^{\mathrm{T}} & \left(\boldsymbol{C}_{a_{i}} \dot{\boldsymbol{a}}_{i}+\boldsymbol{K}_{a_{i}} \boldsymbol{a}_{i}\right)^{\mathrm{T}}
\end{array}\right]^{\mathrm{T}} \in \Re^{(6+s) \times 1}
$$

where $\boldsymbol{a}_{i}$ is the modal coordinate vector of the $i$-th body, $C_{a_{i}} \in \Re^{s \times s}$ and $\boldsymbol{K}_{a_{i}} \in \Re^{s \times s}$ are the modal damping and stiffness matrices of the $i$-th body, $s$ denotes the highest order of the mode chosen. For the robot system given in Figure 1 , the bodies $B_{2}$ and $B_{3}$ are flexible, so only these two bodies have elastic force. In the simulations, the first six modes of $B_{2}$ and $B_{3}$ are both chosen, so $s=6$ in this paper.

In matrix form, Equation (1) can be written as

$$
\Delta \boldsymbol{v}^{\mathrm{T}}\left(-\boldsymbol{M} \dot{\boldsymbol{v}}-f^{\omega}-\boldsymbol{f}^{u}+\boldsymbol{f}^{\mathfrak{o}}\right)+\Delta P=0
$$

where $\boldsymbol{v}=\left[\boldsymbol{v}_{1}^{\mathrm{T}}, \cdots, \boldsymbol{v}_{n}^{\mathrm{T}}\right]^{\mathrm{T}}$ is the configuration velocity of the system, $\boldsymbol{M}=\operatorname{diag}\left[\boldsymbol{M}_{1}, \cdots, \boldsymbol{M}_{n}\right]$ is the mass matrix $, f^{\mu}=\left[\boldsymbol{f}_{1}^{\mu \mathrm{T}}, \cdots, f_{n}^{\mu \mathrm{T}}\right]^{\mathrm{T}}, \boldsymbol{f}^{\omega}=\left[\boldsymbol{f}_{1}^{\omega \mathrm{T}}, \cdots, f_{n}^{\omega \mathrm{T}}\right]^{\mathrm{T}}$, and $\boldsymbol{f}^{o}=\left[\boldsymbol{f}_{1}^{\mathrm{T}}, \cdots, \boldsymbol{f}_{n}^{\mathrm{T}}\right]^{\mathrm{T}}$ are the elastic force, the velocity-dependent inertia force, and the external force, respectively. 
Based on the single direction recursive construction method, we can write the configuration velocity of the system as [34]

$$
v=G \dot{y}, \dot{v}=G \ddot{y}+g \hat{I}_{N}
$$

where $y \in \Re^{N}$ is the independent generalized coordinate vector of the robot system, composed of the generalized coordinates of the robot base $\left(B_{1}\right)$, the joint coordinates of the manipulator, the modal coordinates of the flexible links $B_{2}$ and $B_{3}$, and the generalized coordinates of $B_{6}$ and $B_{7}$. The generalized coordinates of the robot base contain three translational ones and three rotational ones, eight joint coordinates of the manipulator, six modal coordinates of $B_{2}$, and six modal coordinates of $B_{3}$. Therefore, the number of independent generalized coordinates of the robot system is twenty-six, namely $N=26$. The parameters $\boldsymbol{G}, \boldsymbol{g}$, and $\hat{\boldsymbol{I}}_{N}$ in Equation (4) are all constant matrices or vectors, and their expressions can be found in Ref. [30].

Using Equations (3) and (4), Equation (3) can be written as

$$
\Delta \dot{y}^{\mathrm{T}}\left[-Z \ddot{y}-\boldsymbol{z}+\boldsymbol{h}+\boldsymbol{f}^{\mathfrak{y}}\right]=0
$$

where $\boldsymbol{Z}=G^{\mathrm{T}} \boldsymbol{M G}, \boldsymbol{z}=G^{\mathrm{T}}\left(\boldsymbol{f}^{\omega}+\boldsymbol{f}^{\boldsymbol{u}}+\boldsymbol{M} \hat{\boldsymbol{g}} \hat{\mathbf{I}}_{N}\right)$ and $\boldsymbol{h}=\boldsymbol{G}^{\mathrm{T}} \boldsymbol{f}^{\rho}$, and $\boldsymbol{f}^{\boldsymbol{y} y}$ is the vector of the generalized force of the system.

Since all the elements of $y$ are independent, Equation (5) becomes

$$
-Z \ddot{y}-z+h+f^{y}=0
$$

This formula is the dynamic equation of the flexible space robot system. We have established the dynamic model for this system, for details please see Ref. [34].

\section{Contact Model}

This section presents the contact model between the robot and the target. Today there are two main methods to analyze impact and contact between contact objects. One is the momentum method. In this method, impact impulse is used instead of contact force in impact analysis. The contact process is considered as a discontinuous process divided into two phases: pre-contact and post-contact. Comparatively, in the other method, the contact process is considered as a continuous process, and contact force acts on the contact objects until they separate. Compared with the first method, the second method gives a better description of the real contact behavior. More importantly, the second method can be applied to complex contact problems such as multi-object contact. The Hertz contact theory is a typical example of the second method and has had many applications in practice [35].

In this paper, the Hertz contact theory is used to model the contact dynamics of the robot system, and computer graphics are employed to detect the interference between the end effecter and the target object. For simplicity of description, the target object is modeled as a rigid cylinder, as shown in Figure 1, it may simulate the handle of a target spacecraft or other structures with a similar shape which are captured.

\subsection{Contact Force}

In the research on contact mechanics, some contact force models have been proposed, such as the linear Hertz model, the linear Hook model, and the nonlinear Hertz model. The linear Hertz model is the most classical of these models, and it has been successfully used to deal with small deformation contact problems. For the problem of target capture by space robots, considerable contact deformation is harmful to the capturing operation, so the material of the end effecter and the contact point of the captured target both have high stiffness. Therefore, the linear Hertz theory can describe the contact behavior of the 
robot capture. In the linear Hertz theory, the contact force is a non-linear power function of penetration depth and can be written as [35]

$$
F_{c}=\frac{4}{3} E^{*} R^{1 / 2} \hat{d}^{e}
$$

where $R$ is the radius of the cylinder, $\hat{d}$ is the penetration depth, $e$ is an exponent, $e=1.5$ is taken in this paper, and $E^{*}$ is the material stiffness that is given by

$$
\left(E^{*}\right)^{-1}=\left(1-v_{1}^{2}\right) / E_{1}+\left(1-v_{2}^{2}\right) / E_{2}
$$

where $E_{1}$ and $E_{2}$ are the elastic modulus, and $v_{1}$ and $v_{2}$ are the Poisson's ratios of the two contact objects, respectively.

\subsection{Contact Detection and Penetration Depth Calculating}

It can be seen from Figure 1 that the end effecter is composed of three cylinders, and the target object is a cylinder too. Thus, the contact between the end effecter and the target can be converted to the contact among the cylinders. The target object $B_{8}$ is assumed to be inside the two hands $B_{6}$ and $B_{7}$ during the capturing process, so the point contact is the only existing form of contact between $B_{8}$ and the two hands. The contact detection is introduced below.

Figure 2 shows the contact of the target object $B_{8}$ with one hand of $B_{6}$, where $H J$ and EF are the cylinder axes of Hand 1-1, and the two cylinders of Hand 1-1 have the same radius and are represented by $r_{1} ; X I$ is the axis of $B_{8}$ and its radius is $r_{2}$. To detect the distance between two axes, we need to calculate the closest point of the two axes first. Let the axes $H J$ and $X I$ be specified parametrically by the points $H, I, X$ and $J$, given by [36].

\section{Hand 1-1 of end effecter}

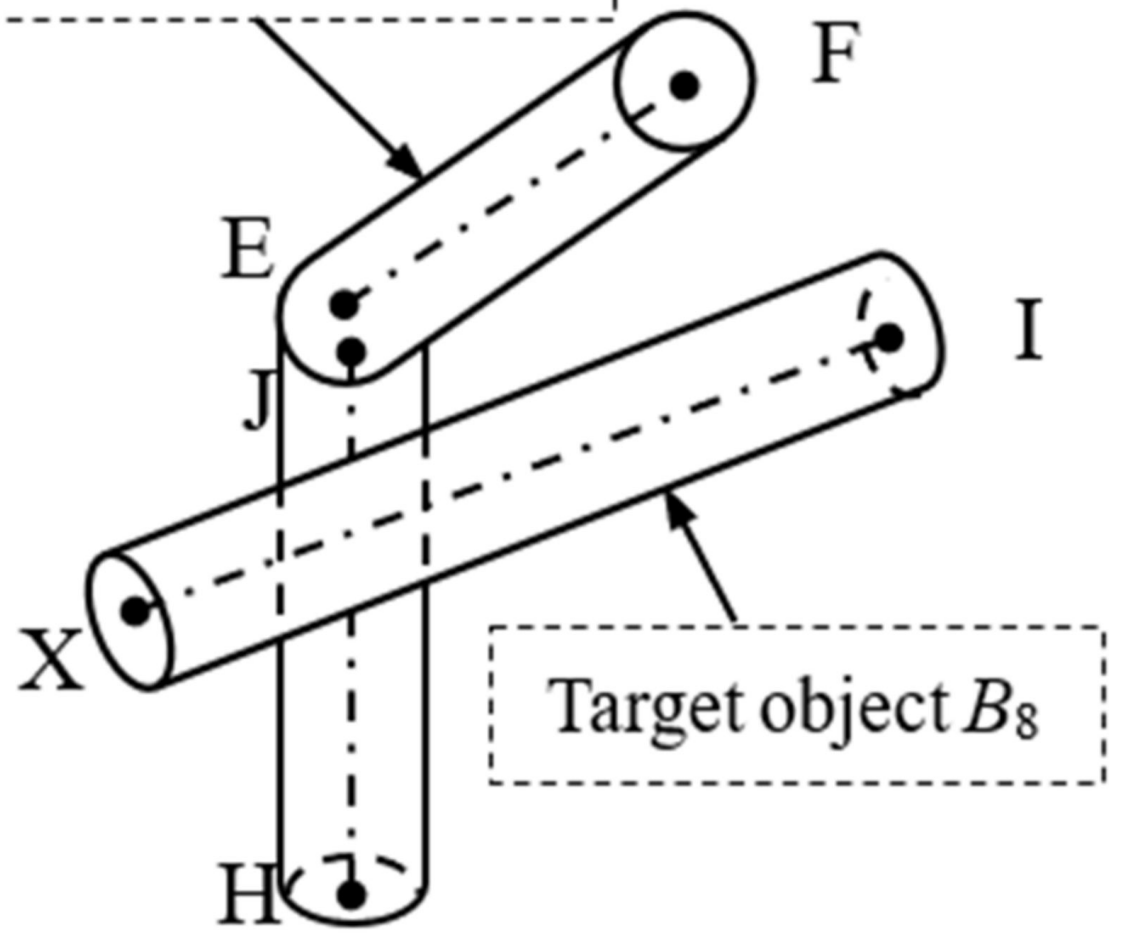

Figure 2. Schematic diagram of contact detection. 


$$
\begin{aligned}
& \boldsymbol{L}_{1}(s)=\boldsymbol{H}+s \boldsymbol{d}_{1}, \boldsymbol{d}_{1}=\boldsymbol{J}-\boldsymbol{H} \\
& \boldsymbol{L}_{2}(t)=\boldsymbol{X}+q \boldsymbol{d}_{2}, \boldsymbol{d}_{2}=\boldsymbol{I}-\boldsymbol{X}
\end{aligned}
$$

For some pairs of values, for example, for $s$ and $q, L_{1}(s)$ and $L_{2}(q)$ correspond to the points on the lines, and $v(s, q)=\boldsymbol{L}_{1}(s)-\boldsymbol{L}_{2}(q)$ describes a vector between them. When the segments $L_{1}$ and $L_{2}$ do not intersect each other, if $v(s, q)$ is perpendicular to both lines $L_{1}$ and $L_{2}$, the points $L_{1}(s)$ and $L_{2}(q)$ are the closest points on the lines. For nonparallel lines, $v(s, q)$ is unique. Based on the definition of perpendicularity constrains, we can obtain

$$
\boldsymbol{d}_{1} \cdot \boldsymbol{v}(s, q)=0, \boldsymbol{d}_{2} \cdot \boldsymbol{v}(s, q)=0
$$

Considering Equation (9) and the parametric equation of $v(s, q)$, we can get

$$
\begin{aligned}
& \boldsymbol{d}_{1} \cdot\left(\boldsymbol{L}_{1}(s)-\boldsymbol{L}_{2}(q)\right)=\boldsymbol{d}_{1} \cdot\left((\boldsymbol{H}-\boldsymbol{J})+s \boldsymbol{d}_{1}-q \boldsymbol{d}_{2}\right)=0 \\
& \boldsymbol{d}_{2} \cdot\left(\boldsymbol{L}_{1}(s)-\boldsymbol{L}_{2}(q)\right)=\boldsymbol{d}_{2} \cdot\left((\boldsymbol{H}-\boldsymbol{J})+s \boldsymbol{d}_{1}-q \boldsymbol{d}_{2}\right)=0
\end{aligned}
$$

This can be expressed as the $2 \times 2$ system of linear equations

$$
\begin{aligned}
& \left(\boldsymbol{d}_{1} \cdot \boldsymbol{d}_{1}\right) s-\left(\boldsymbol{d}_{1} \cdot \boldsymbol{d}_{2}\right) q=-\boldsymbol{d}_{1} \cdot(\boldsymbol{H}-\boldsymbol{J}) \\
& \left(\boldsymbol{d}_{2} \cdot \boldsymbol{d}_{1}\right) s-\left(\boldsymbol{d}_{2} \cdot \boldsymbol{d}_{2}\right) q=-\boldsymbol{d}_{2} \cdot(\boldsymbol{H}-\boldsymbol{J})
\end{aligned}
$$

Solving Equation (12), we can get $s$ and $q$. Substituting them into Equation (9), we can obtain $L_{1}(s)$ and $L_{2}(q)$. Regarding $d$ as the distance between $L_{1}(s)$ and $L_{2}(q)$, if $d<r_{1}+r_{2}$, the two cylinders have contacted, and the penetration depth is $\hat{d}=r_{1}+r_{2}-d$.

\section{Controller Design for the Manipulator}

In capturing process, big impacts between the robot and the non-cooperative target may result in the damage of the manipulator or disorder of the robot attitude. In this paper, an active compliance controller is designed to eliminate the impact of collision. Next, the derivation process of the controller is given as follows.

The dynamic equation of the space robot system (Equation (6)) involving the capturing operation can be written as

$$
Z \ddot{y}+z=F_{c}+u
$$

where $\boldsymbol{u}=\boldsymbol{f}^{y}$ is the vector of control force that is generated by electrical motors installed on the joints, and $\boldsymbol{F}_{c}=\boldsymbol{h}$ is the vector of contact force on the end effecter. It is reasonable to predict that, in the case $\boldsymbol{F}_{c} \neq 0$, the desired coordinates $\boldsymbol{y}_{d}$ of the robot system are no longer ensured. Inspired by the passive compliance control method, the system equation can be written as

$$
Z \ddot{y}+D\left(\dot{y}-\dot{y}_{d}\right)+K\left(y-y_{d}\right)=F_{c}
$$

where $K$ and $D$ are the active stiffness weighting and active damping weighting, respectively. To obtain Equation (14), the controller should be

$$
u=z-D\left(\dot{y}-\dot{y}_{d}\right)-K\left(y-y_{d}\right)
$$

From Equations (14) and (15) we can find that the response of the robot system to the contact force depends not only on the inertia parameters $(Z)$ of the robot system but also on the compliance parameters $(\boldsymbol{K}$ and $\boldsymbol{D})$ of the controller. Therefore, the system response can be lowered by choosing suitable compliance parameters of the controller. Thus, the influence of impact is reduced.

\section{Numerical Simulations}

This section will carry out simulations to demonstrate the effectiveness of theoretical studies. As shown in Figure 1, the robot base is assumed to be a big rigid cylinder, of which 
the length is $24 \mathrm{~m}$, and the radius is $1 \mathrm{~m}$. The lengths of the four links $\left(B_{2}, B_{3}, B_{4}\right.$, and $\left.B_{5}\right)$ of the manipulator are $6.4 \mathrm{~m}, 7 \mathrm{~m}, 0.5 \mathrm{~m}$, and $0.6 \mathrm{~m}$, respectively. The first six modes of the flexible links $B_{2}$ and $B_{3}$ are considered in this paper, and the free-pinned beam's modal functions are both used. The first six natural frequencies of $B_{2}$ are $5.9076 \mathrm{~Hz}, 25.8648 \mathrm{~Hz}$, $368,781 \mathrm{~Hz}, 834,175 \mathrm{~Hz}, 1,026,270 \mathrm{~Hz}$, and $172,7682 \mathrm{~Hz}$, respectively, and those of $B_{3}$ are $54,859 \mathrm{~Hz}, 240,087 \mathrm{~Hz}, 342,174 \mathrm{~Hz}, 773,491 \mathrm{~Hz}, 951,008 \mathrm{~Hz}$, and 1,599,500 Hz. The space object is also assumed to be a rigid cylinder and its radius is $R=0.05 \mathrm{~m}$. It is used to simulate the handle of a target spacecraft or other structures with a similar shape to be captured. The end effecters and the targets are steel, so Young's modulus and Poisson's ratio in Equations (7) and (8) are $E_{1}=E_{2}=2.06 \times 10^{11}$ and $v_{1}=v_{2}=0.3$. The other physical parameters of the robot system are given in Table 1. The space robot shown in Figure 1a is like the Shuttle Remote Manipulator System (SRMS) designed by the Canadian Space Agency (CSA).

Table 1. Physical parameters of the space robot.

\begin{tabular}{|c|c|c|c|c|c|c|c|}
\hline Body & Mass (kg) & $I_{x x}\left(\mathrm{~kg} \cdot \mathrm{m}^{2}\right)$ & $I_{y y}\left(\mathrm{~kg} \cdot \mathrm{m}^{2}\right)$ & $I_{z z}\left(\mathrm{~kg} \cdot \mathrm{m}^{2}\right)$ & $E I\left(\mathbf{N} \cdot \mathbf{m}^{2}\right)$ & $G J\left(\mathbf{N} \cdot \mathbf{m}^{2}\right)$ & $E A(\mathrm{~N})$ \\
\hline$B_{1}$ & $1.0179 \times 10^{5}$ & $5.0894 \times 10^{6}$ & $4.9113 \times 10^{6}$ & $4.9113 \times 10^{6}$ & & & \\
\hline$B_{2}$ & 138 & 0.399 & 471.82 & 471.82 & $4.04 \times 10^{6}$ & $2.040 \times 10^{6}$ & $2.8 \times 10^{9}$ \\
\hline$B_{3}$ & 85.06 & 0.4 & 348.01 & 348.01 & $2.81 \times 10^{6}$ & $1.417 \times 10^{6}$ & $1.2 \times 10^{9}$ \\
\hline$B_{4}$ & 8 & 0.2 & 0.76 & 0.76 & & & \\
\hline$B_{5}$ & 41 & 0.2 & 5.02 & 5.02 & & & \\
\hline$B_{6}$ & 12.25 & 0.163 & 0.136 & 0.2759 & & & \\
\hline$B_{7}$ & 6.125 & 0.082 & 0.0068 & 0.0767 & & & \\
\hline$B_{8}$ & 480.35 & 1.18 & 0.7 & 0.7 & & & \\
\hline
\end{tabular}

As shown in Figure 1, frame $O-X Y Z$ is an absolute reference frame; frame $O_{1}-X_{1} Y_{1} Z_{1}$ paralleling to the frame $O-X Y Z$ fixes on the robot base $B_{1}$ and the origin $O_{1}$ is on the mass center of $B_{1}$. Floating frames $O_{2}-X_{2} Y_{2} Z_{2}$ and $O_{3}-X_{3} Y_{3} Z_{3}$ fix on the two links $B_{2}$ and $B_{3}$, respectively, and the origins $O_{2}$ and $O_{3}$ are on the mass centers of the two links. Furthermore, frames $O_{6}-X_{6} Y_{6} Z_{6}$ and $O_{7}-X_{7} Y_{7} Z_{7}$ fixed on the body $B_{5}$ are used to describe the relative rotational motion of the two hands of the end effecter with respect to the body $B_{5}$. In the simulations, the initial joint angles of $B_{2}-B_{5}$ are chosen as $\left({ }^{\circ} 30^{\circ}-57.2041^{\circ}\right.$ $27.2038^{\circ} 0^{\circ} 0^{\circ}$ ), where the axes of $B_{4}$ and $B_{5}$ are both parallel to the $Y$ axis. The space robot is in the $O-Y Z$ plane before capturing. The initial and final positions of $B_{6}$ and $B_{7}$ are shown in Figure 3. The robot base is free-floating during capturing, while only the robot manipulator and the end-effecter are controlled. The desired angular velocities of the manipulator $\left(B_{2}-B_{5}\right)$ are all zero.

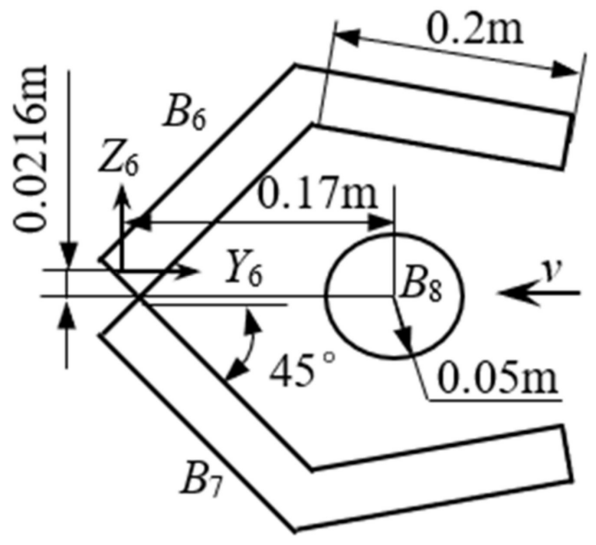

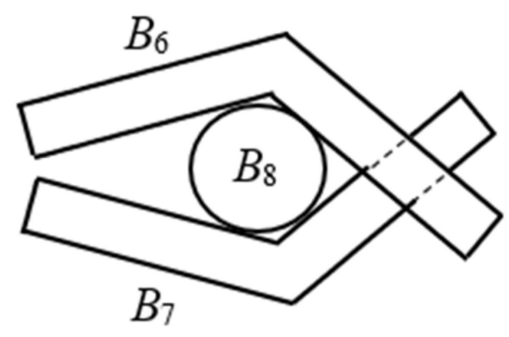

(a)

(b)

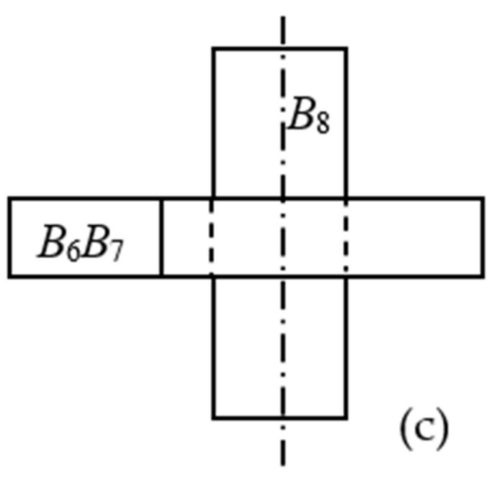

(c)

Figure 3. Positions of the two hands and the captured object: (a) initial position, (b) final position, and (c) grasped position of $B_{8}$. 
The effectiveness of the active controller designed in Section 4 is verified firstly. The relative position of mass center of the target cylinder $B_{8}$ in the $O_{1}-X_{1} Y_{1} Z_{1}$ frame is $(0 \mathrm{~m}$, $25.05 \mathrm{~m}, 1 \mathrm{~m})$ and the cylinder axis parallels the $X_{1}$ axis. The absolute angular velocity and the absolute translation velocity of the target cylinder $B_{8}$ are $(0,0,0)$ and $(0,-0.05 \mathrm{~m} / \mathrm{s}$ $(-0.1 \mathrm{~m} / \mathrm{s}), 0)$, respectively, namely $B_{8}$ moves toward the space robot at $0.05 \mathrm{~m} / \mathrm{s}$ and $0.1 \mathrm{~m} / \mathrm{s}$ along the $Y$ direction. Since the robot is at rest before impact, the absolute velocity of $B_{8}$ is the relative one. The robot will grasp the middle position of $B_{8}$, as shown in Figure $3 \mathrm{c}$. The following two control cases are considered in the simulations:

Case 1: the six joints of the manipulator are locked and the manipulator can be regarded as one body. The two hands $B_{6}$ and $B_{7}$ of the end effecter are only controlled in the capture of the target. In controller design, the matrices $\boldsymbol{K}$ and $\boldsymbol{D}$ in Equation (15) are both $26 \times 26$ matrices, and all elements of $K$ and $D$ are chosen to be zeros except $K_{25,25}=K_{26,26}=200$ and $D_{25,25}=D_{26,26}=50 . K_{25,25}, K_{26,26}, D_{25,25}$, and $D_{26,26}$ correspond to the control weightings of $B_{6}$ and $B_{7}$. The desired rotational velocities of $B_{6}$ and $B_{7}$ are both $0.1 \mathrm{rad} / \mathrm{s}$.

Case 2: the six joints of the manipulator and the two hands $B_{6}$ and $B_{7}$ are all controlled in capturing the target. For this case, active compliance controls are applied on the six joints of the manipulator to offset the capture of the robot. In controller design, all elements of $K$ are chosen to be zeros except $K_{25,25}=K_{26,26}=200$, and $\boldsymbol{D}$ is chosen as $\boldsymbol{D}=\operatorname{diag}\left[\boldsymbol{0}_{1 \times 6} 100\right.$ $100 \boldsymbol{0}_{1 \times 6} 100 \boldsymbol{0}_{1 \times 6} 10010010050$ 50]. The first $\boldsymbol{0}_{1 \times 6}$ in $\boldsymbol{D}$ is the control weighting of the robot base, the second and third $\boldsymbol{0}_{1 \times 6}$ are the control weightings of modal coordinates of the two flexible links $B_{2}$ and $B_{3}$, respectively; and the six 100 are the control weightings of six joint coordinates of the manipulator. The desired rotational velocities of $B_{6}$ and $B_{7}$ are both $0.1 \mathrm{rad} / \mathrm{s}$ too.

Figure 4 depicts the state of the space robot in the pre-capture and post-capture phases. Figures 5-8 present the simulation results for Cases 1 and 2, where Figures 5 and 7 are the time histories of the attitude of the robot base, and Figures 6 and 8 are those of the rotation angle of the hands $B_{6}$ and $B_{7}$; the solid line represents the results of Case 1 and the dotted line Case 2. From Figures 5 and 7, it can be observed that capturing operation only causes the plane motion of the robot system and does not produce rotational motions in the $Y$ and $\mathrm{Z}$ directions. This is because the space robot is initially in the O-YZ plane, and the middle position of the target is grasped. The change in rotational angle of the robot base around the $X$-axis using an active compliance controller is smaller than that without using the controller, which demonstrates the effectiveness of the controller in reducing the capture impact on the robot. From Figures 6 and 8, we can observe that the target can finally be firmly grasped for the two cases.
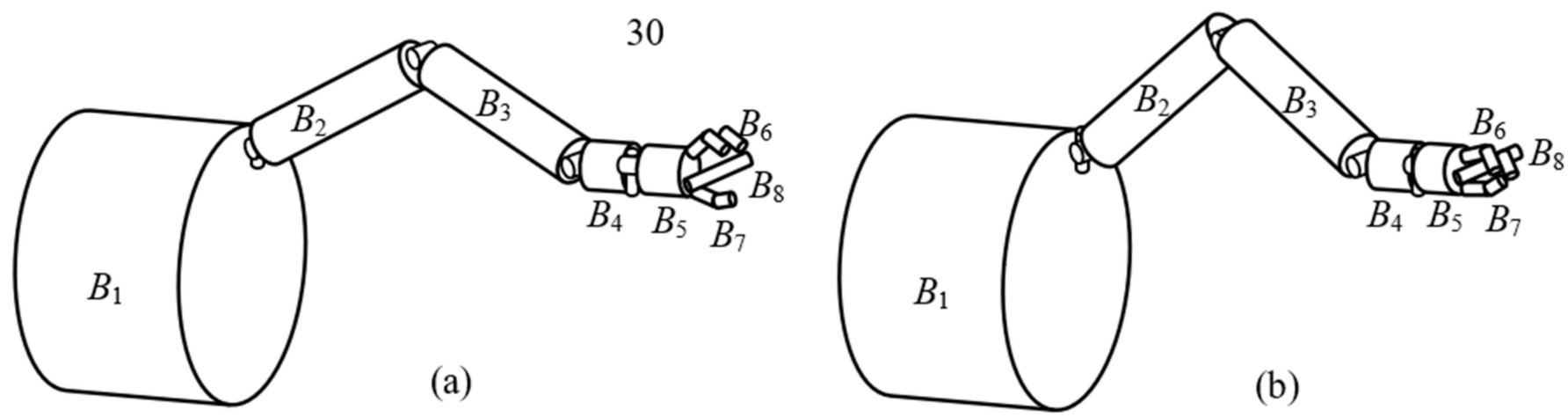

Figure 4. State of the space robot in the process of capturing: (a) pre-capture, and (b) post-capture. 

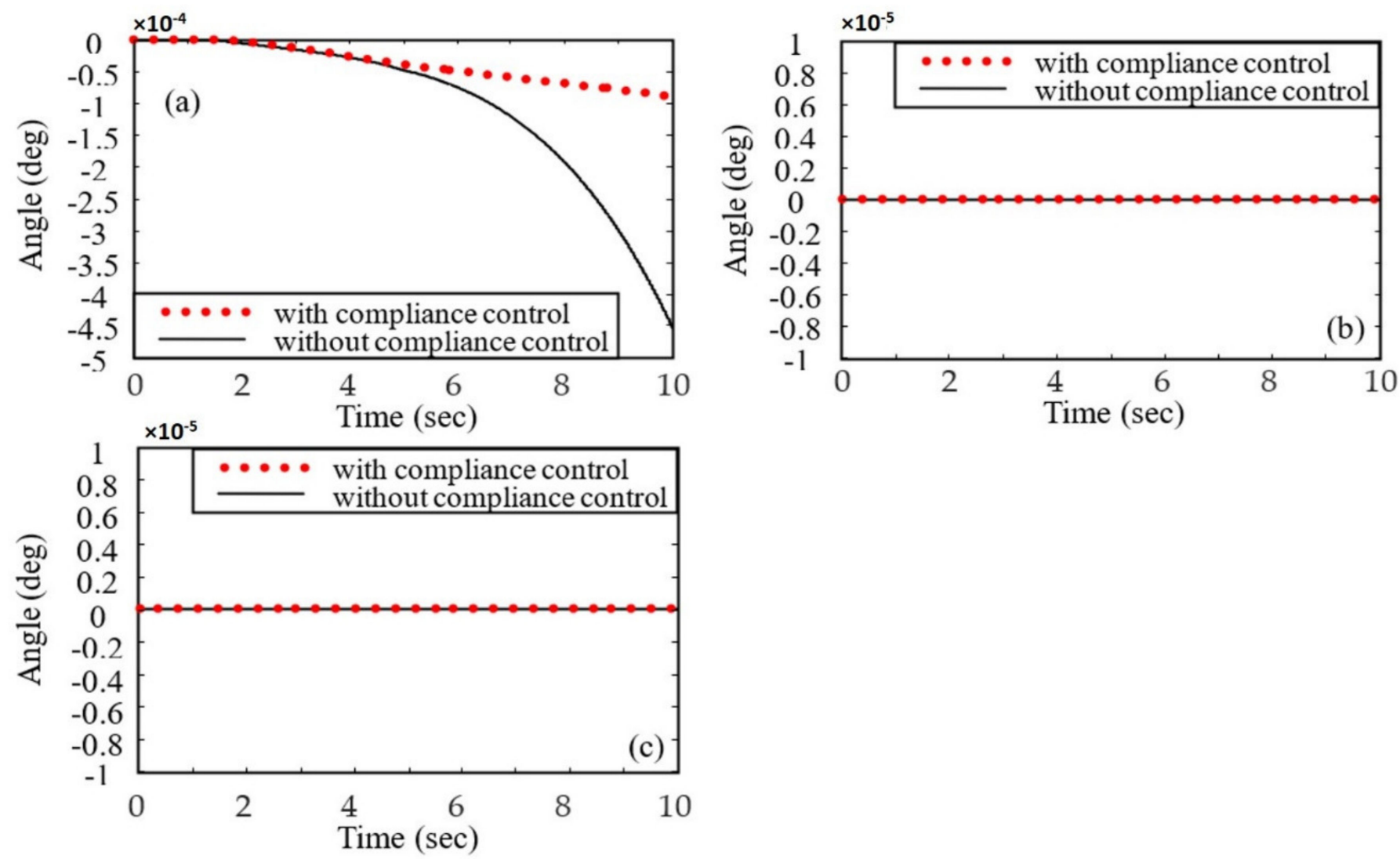

Figure 5. Time histories of angular displacement of the robot base $B_{1}$ with and without active compliance control of the manipulator $(0.05 \mathrm{~m} / \mathrm{s})$ : (a) the $X$ axis, $(\mathbf{b})$ the $Y$ axis, and (c) the $Z$ axis.
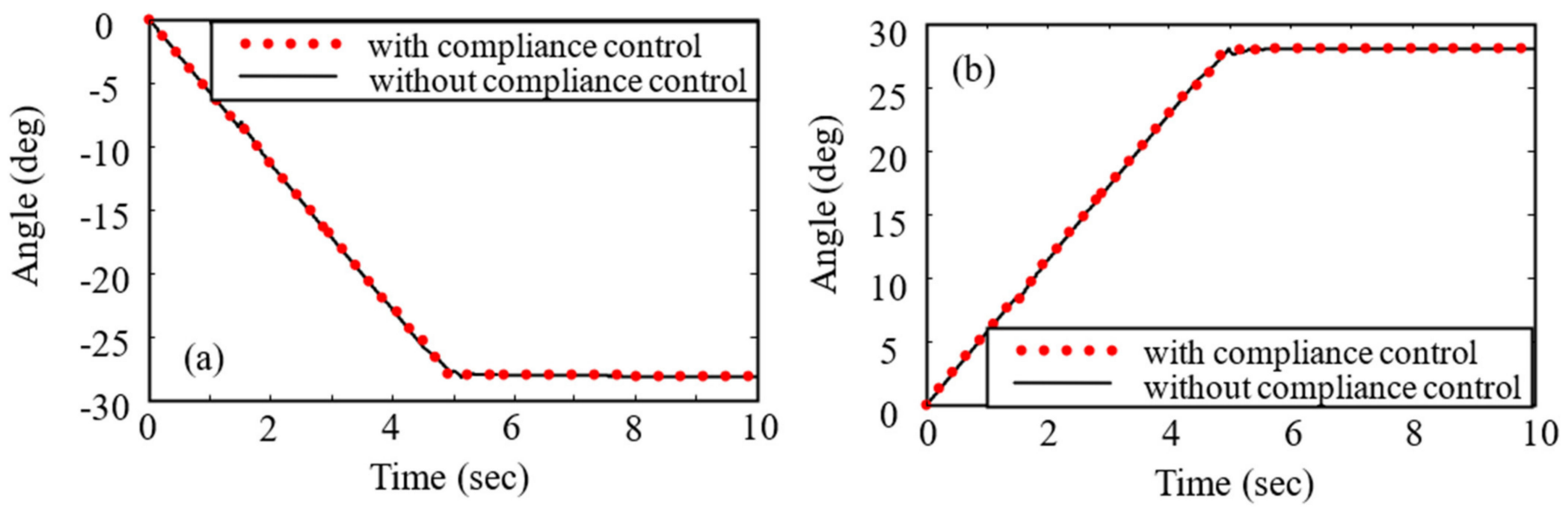

Figure 6. Time histories of rotation angle of the two hands $B_{6}$ and $B_{7}$ with and without active compliance control of the manipulator $(0.05 \mathrm{~m} / \mathrm{s})$ : (a) $B_{6}$, and (b) $B_{7}$. 

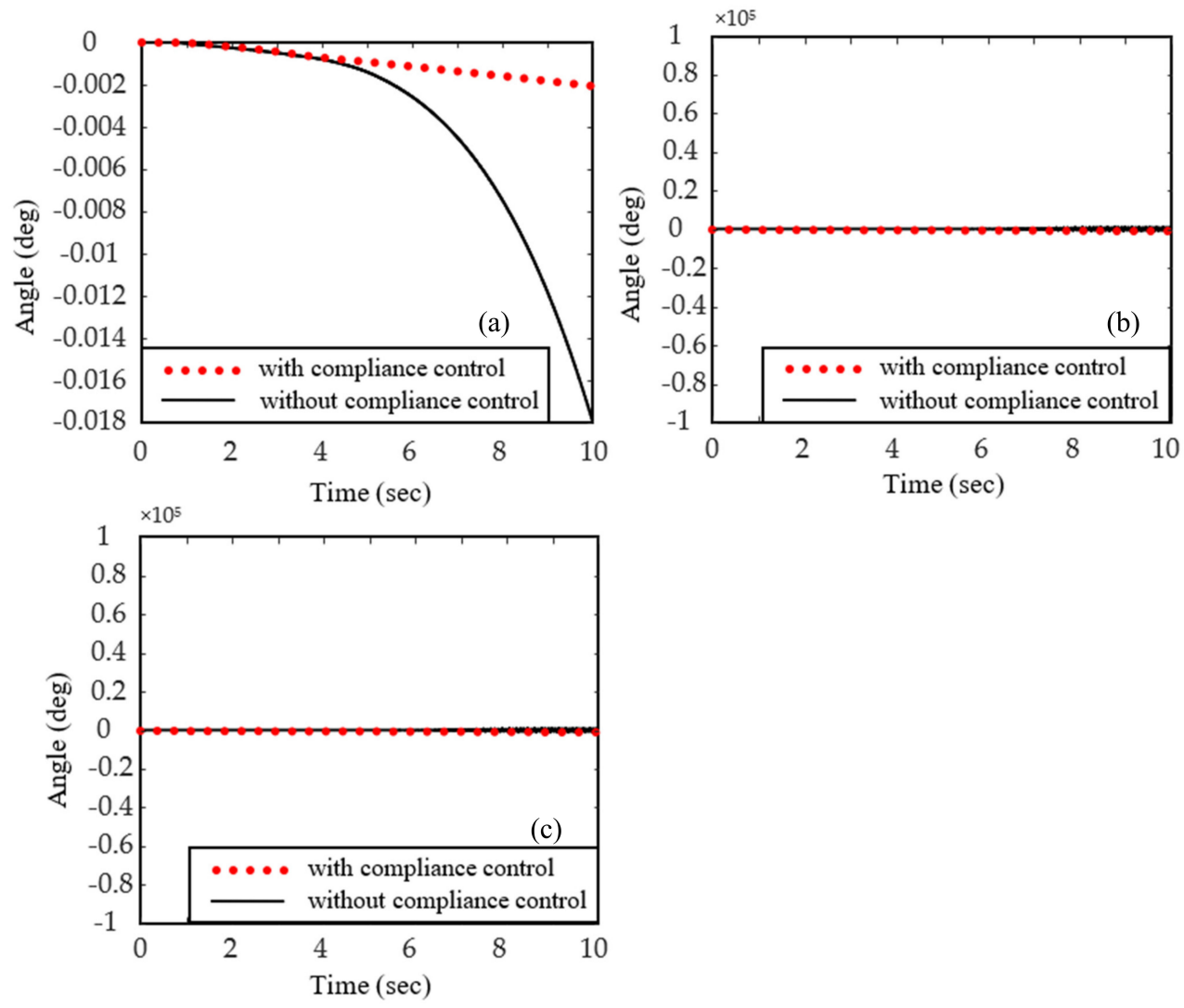

Figure 7. Time histories of angular displacement of the robot base $B_{1}$ with and without active compliance control of the manipulator $(0.1 \mathrm{~m} / \mathrm{s})$ : (a) the $X$ axis, (b) the $Y$ axis, and (c) the $Z$ axis.
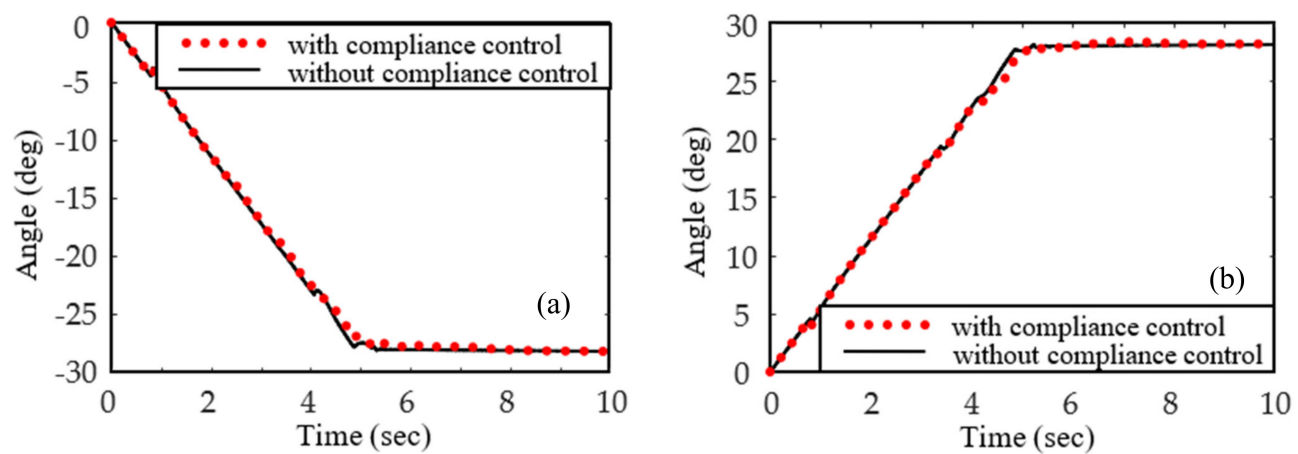

Figure 8. Time histories of rotation angle of the two hands $B_{6}$ and $B_{7}$ with and without active compliance control of the manipulator $(0.1 \mathrm{~m} / \mathrm{s})$ : (a) $B_{6}$, and (b) $B_{7}$.

The results above indicate that the active compliance control of the manipulator could effectively reduce the capture impact on the robot. Next, extensive simulations are conducted to further demonstrate the influence of impact. The four impact cases shown in Figure 9 are considered. In these cases, the $Y_{1}$ and $Z_{1}$ positions of the mass center of the target cylinder $B_{8}$ in the $O_{1}-X_{1} Y_{1} Z_{1}$ frame are $25.05 \mathrm{~m}$ and $1 \mathrm{~m}$, respectively, and the cylinder axis parallels the $X_{1}$ axis. For the first and second impact cases (Figures $8 b$ and $9 a$ ), the relative position of the mass center of the target cylinder in the $X_{1}$ direction is $0 \mathrm{~m}$, and the impact is central impact, and for the third and fourth impact cases (Figures $8 \mathrm{~d}$ and $9 \mathrm{c}$ ), the relative position is $0.05 \mathrm{~m}$, and the impact is eccentric impact. In these two cases, the tumbling motion of $B_{8}$ caused by the capturing operation will appear. Assume that $v$ is the relative velocity between the target cylinder $B_{8}$ and the end effecter. Two different relative velocities, $v=0.05 \mathrm{~m} / \mathrm{s}$ and $v=0.1 \mathrm{~m} / \mathrm{s}$, are considered in the simulations. The absolute angular velocity of the target cylinder $B_{8}$ is $(0,0,0)$ and the absolute translation velocity of 
the target cylinder $B_{8}$ is $(0, v \mathrm{~m} / \mathrm{s}, 0)$ for the first and third impact cases (Figure $\left.9 \mathrm{a}, \mathrm{c}\right)$, and they are $(0,0,0)$ and $(0,-v \mathrm{~m} / \mathrm{s}, 0)$ for the second and fourth impact cases (Figure 9b,d). In other words, the target cylinder $B_{8}$ moves at a constant speed $v \mathrm{~m} / \mathrm{s}$ along the $Y$ direction with no rotation towards or away from the robot. The six joints of the manipulator and the two hands $B_{6}$ and $B_{7}$ are all controlled in the capturing process. In controller design, $K$ and $D$ are chosen as the same as those in Case 2, namely all elements of $K$ are chosen to be zeros except $K_{25,25}=K_{26,26}=200$, and $\boldsymbol{D}=\operatorname{diag}\left[\boldsymbol{0}_{1 \times 6} 100100 \boldsymbol{0}_{1 \times 6} 100 \boldsymbol{0}_{1 \times 6} 10010010050\right.$ 50]. The desired rotational velocities of $B_{6}$ and $B_{7}$ are both also $0.1 \mathrm{rad} / \mathrm{s}$. The simulation results are given in Figures 10-19, where Figures 10 and 14 are the attitude change of the robot base $B_{1}$ for $v=0.05 \mathrm{~m} / \mathrm{s}$ and $v=0.1 \mathrm{~m} / \mathrm{s}$, respectively. Figures 11 and 15 are the angular displacement change of the six joints of the robot manipulator, Figures 12 and 16 are the rotation angle change of the two hands of the end effecter, Figures 13 and 17 are the tip responses of the flexible links $B_{2}$ and $B_{3}$ in the floating frames $O_{2}-X_{2} Y_{2} Z_{2}$ and $O_{3}-X_{3} Y_{3} Z_{3}$. Figures 18 and 19 are the attitude change of the target $B_{8}$. The conclusions drawn from Figures 10-19 are:

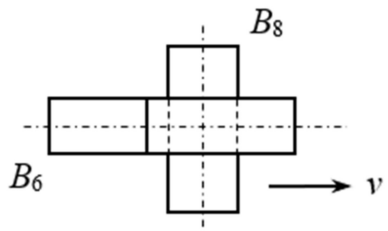

Central impact (First impact case)

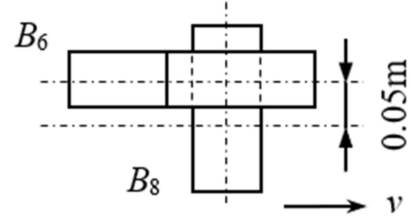

Eccentric impact (Third impact case) (a)

(c)

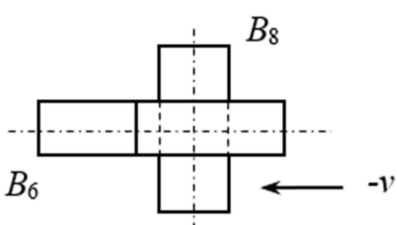

Central impact (Second impact case)

(b)

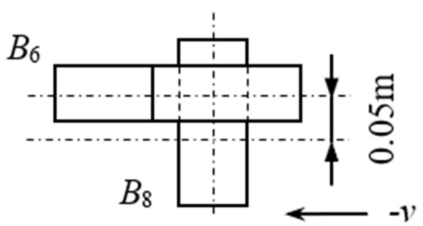

Eccentric impact (Fourth impact case)

Figure 9. Four impact cases.
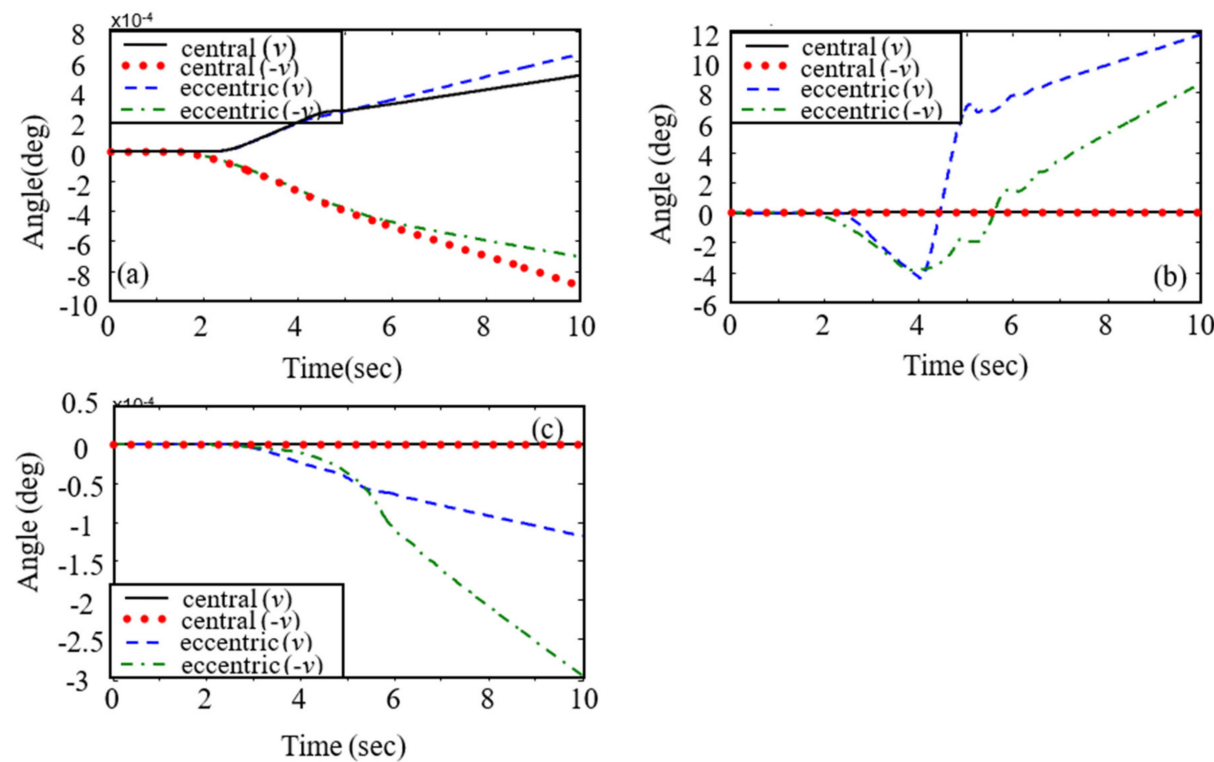

Figure 10. Time histories of angular displacements of the robot base $B_{1}(v=0.05 \mathrm{~m} / \mathrm{s})$ : (a) the $X$ axis, (b) the $Y$ axis, and (c) the $Z$ axis. 

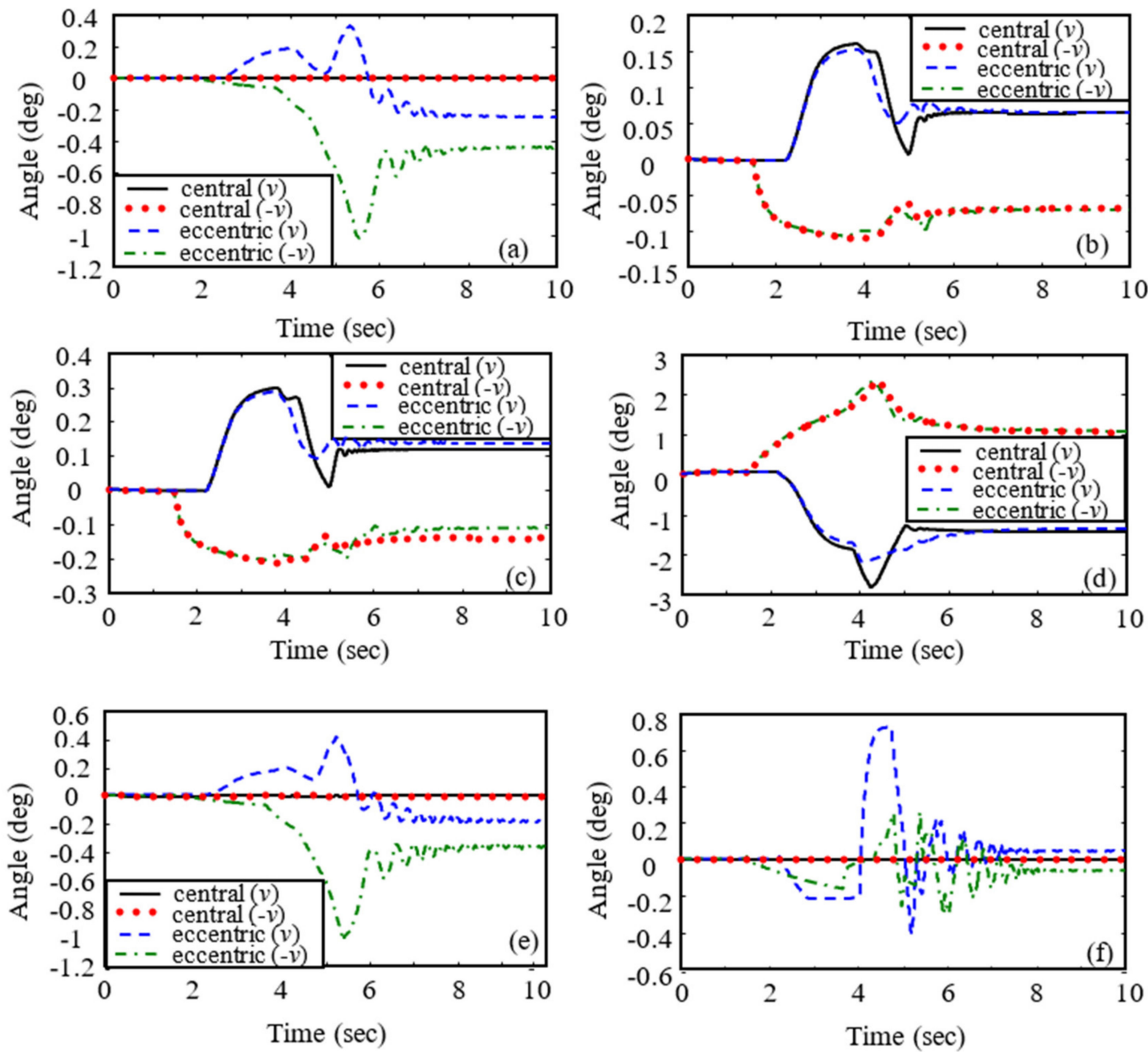

Figure 11. Time histories of angular displacements of the manipulator $(v=0.05 \mathrm{~m} / \mathrm{s})$ : (a) Axis 1 , (b) Axis 2, (c) Axis 3, (d) Axis 4, (e) Axis 5, and (f) Axis 6.
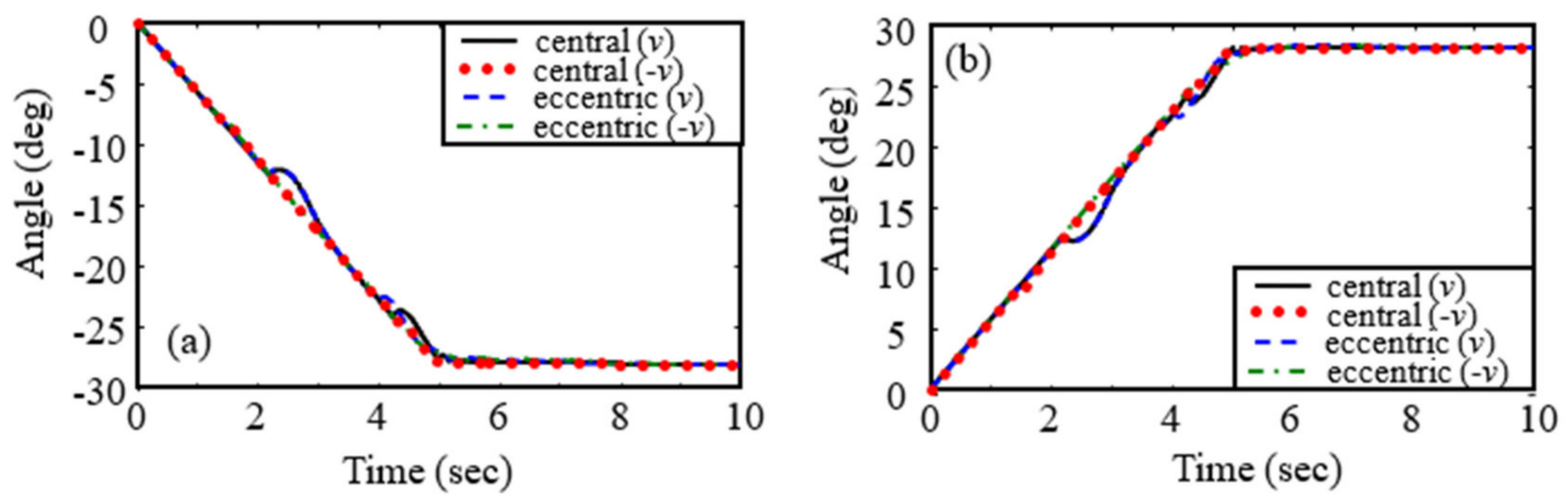

Figure 12. Time histories of the rotation angles of the two hands $(v=0.05 \mathrm{~m} / \mathrm{s})$ : (a) $B_{6}$, (b) $B_{7}$. 

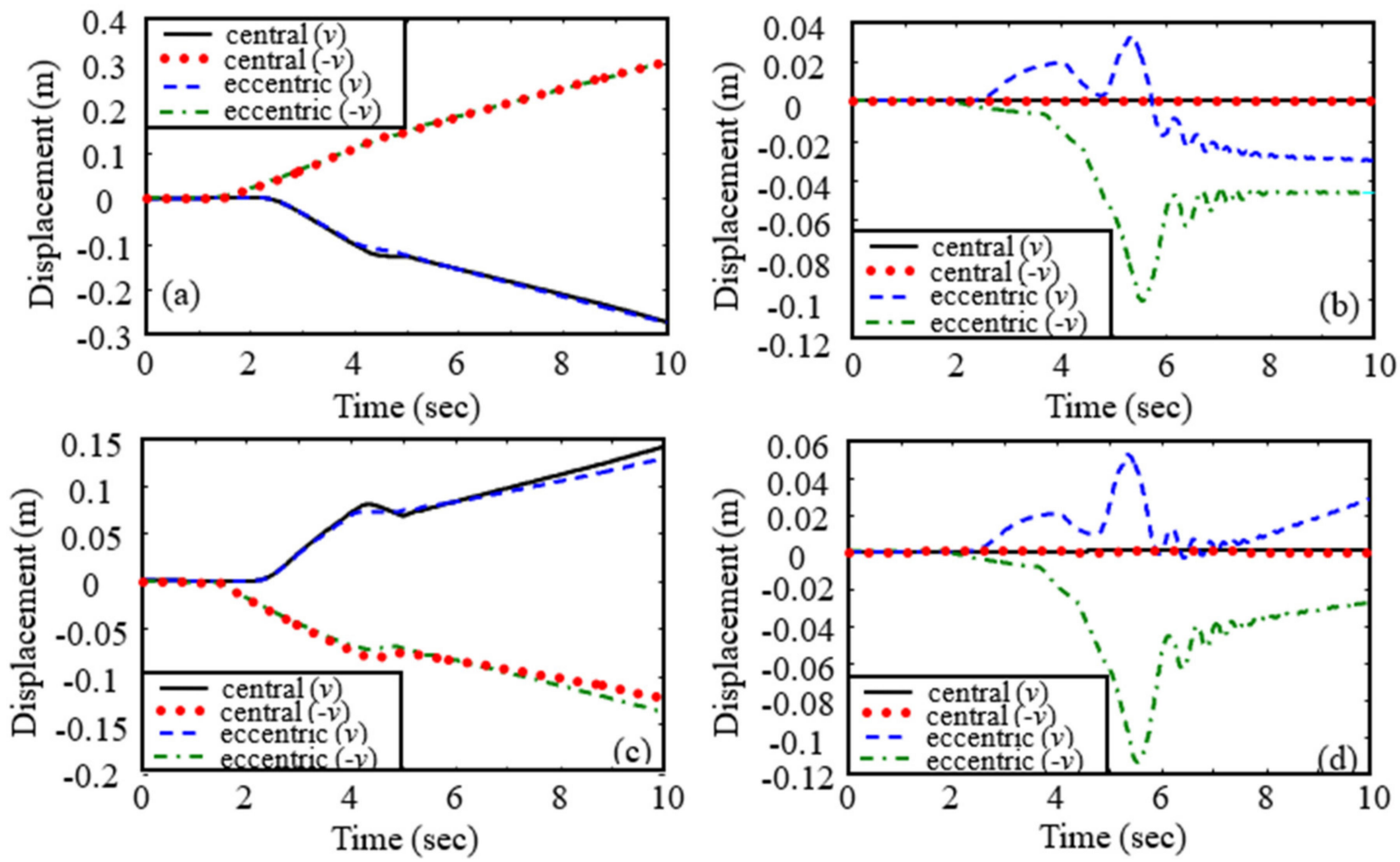

Figure 13. Tip displacements of the flexible links $B_{2}$ and $B_{3}(v=0.05 \mathrm{~m} / \mathrm{s}):(\mathbf{a}) B_{2}$ in the $Y_{2}$ direction, (b) $B_{2}$ in the $Z_{2}$ direction, (c) $B_{3}$ in the $Y_{3}$ direction, and (d) $B_{3}$ in the $Z_{3}$ direction.
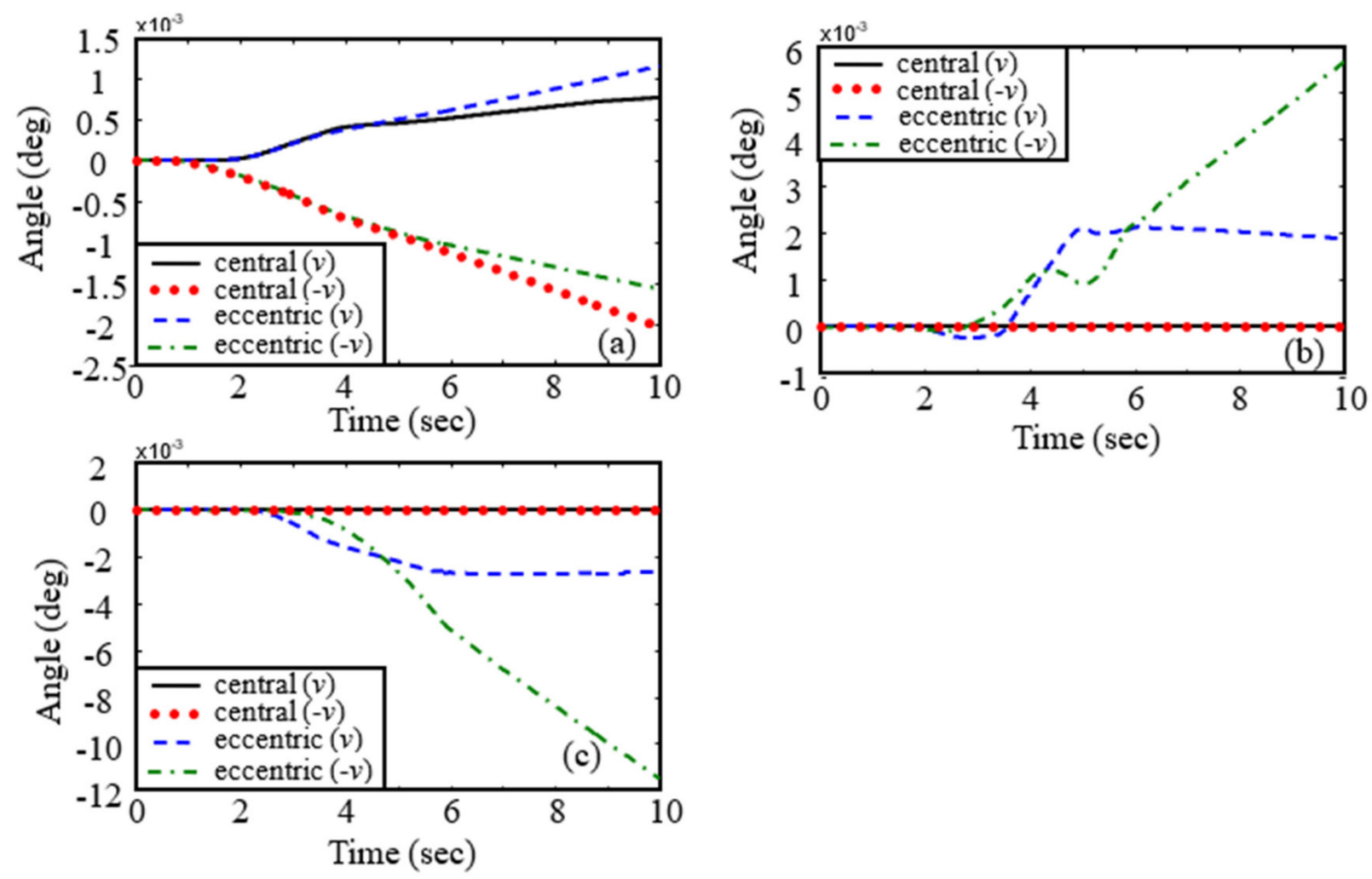

Figure 14. Time histories of angular displacements of the robot base $B_{1}(v=0.1 \mathrm{~m} / \mathrm{s})$ : (a) the $X$ axis, (b) the $Y$ axis, and (c) the $Z$ axis. 

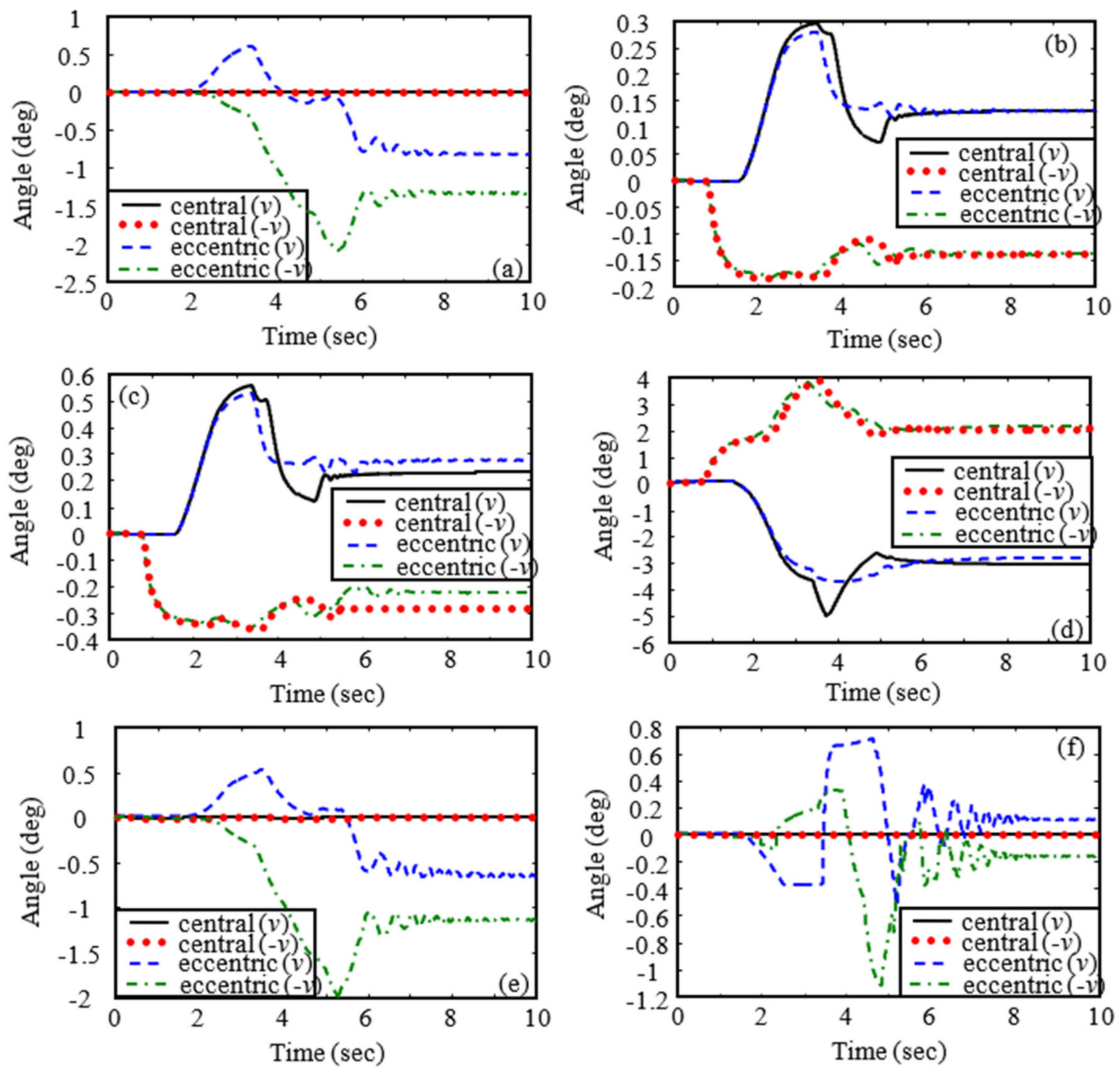

Figure 15. Time histories of angular displacements of the manipulator $(v=0.1 \mathrm{~m} / \mathrm{s})$ : (a) Axis 1 , (b) Axis 2, (c) Axis 3, (d) Axis 4, (e) Axis 5, and (f) Axis 6.
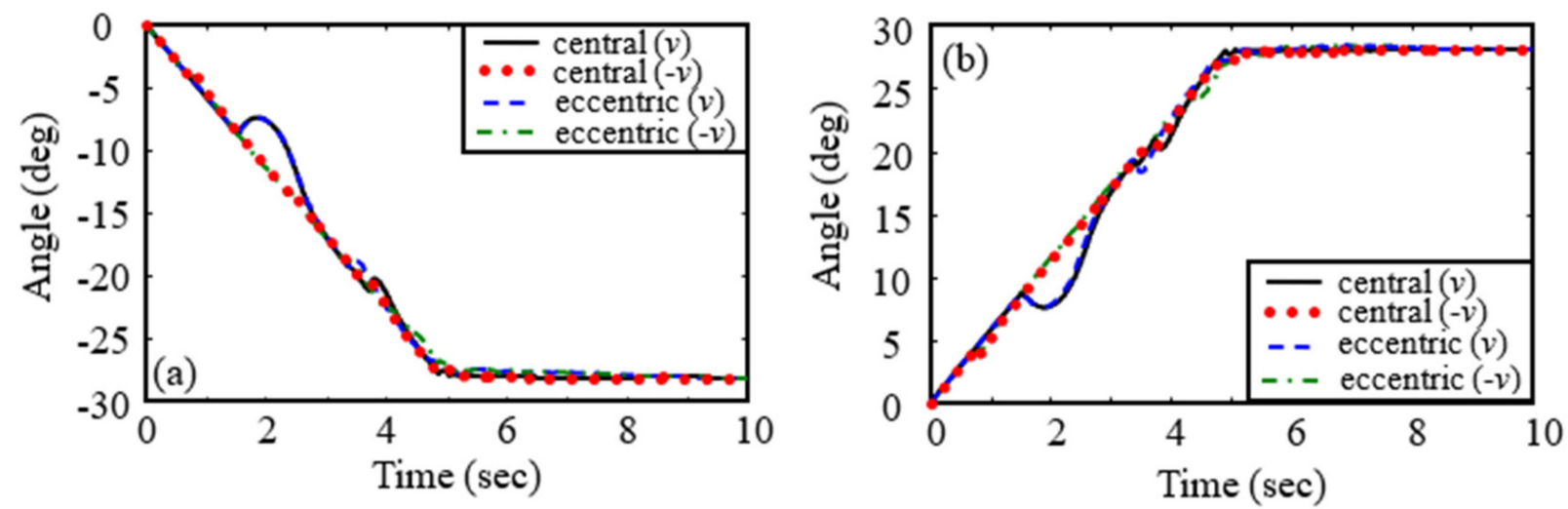

Figure 16. Time histories of the rotation angles of the two hands $(v=0.1 \mathrm{~m} / \mathrm{s}):(\mathbf{a}) B_{6}$, and (b) $B_{7}$. 

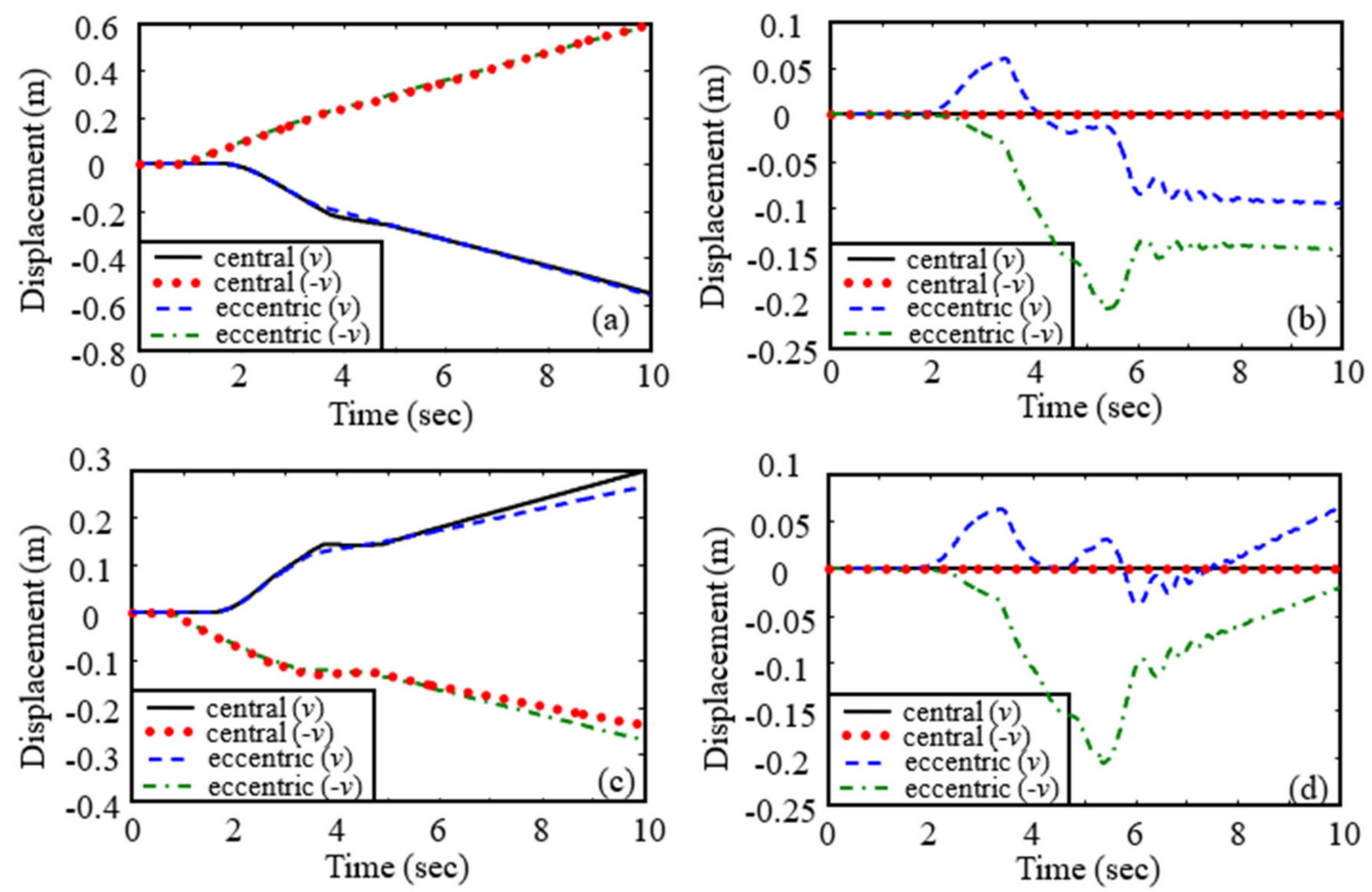

Figure 17. Tip displacements of the flexible links $B_{2}$ and $B_{3}(v=0.1 \mathrm{~m} / \mathrm{s}):(a) B_{2}$ in the $Y_{2}$ direction, (b) $B_{2}$ in the $Z_{2}$ direction, (c) $B_{3}$ in the $Y_{3}$ direction, and (d) $B_{3}$ in the $Z_{3}$ direction.
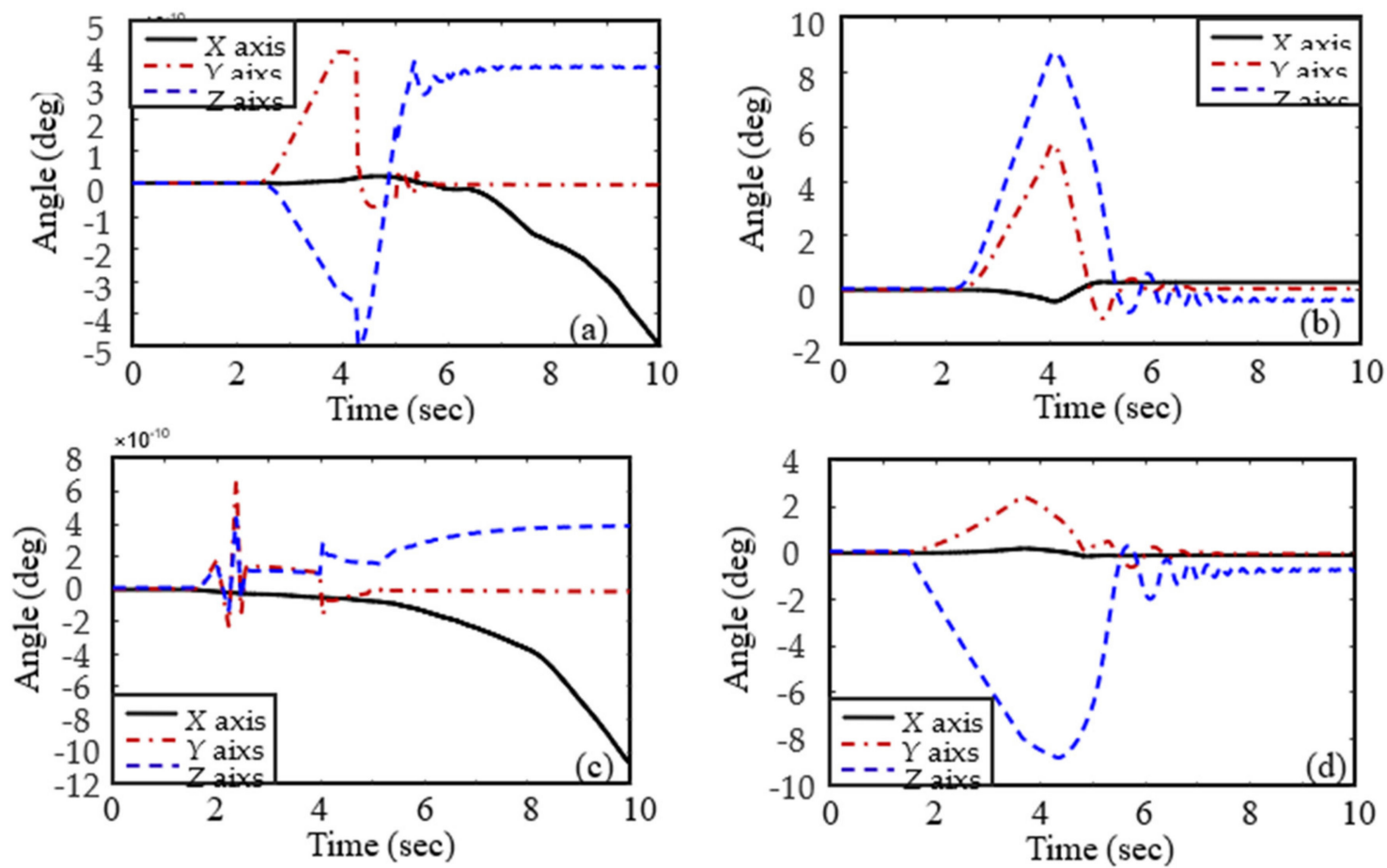

Figure 18. Time histories of angular displacements of the target $B_{8}:(\mathbf{a}) v=0.05 \mathrm{~m} / \mathrm{s},(\mathbf{b}) v=0.05 \mathrm{~m} / \mathrm{s}$, (c) $v=-0.05 \mathrm{~m} / \mathrm{s}$, and (d) $v=-0.05 \mathrm{~m} / \mathrm{s}$. 

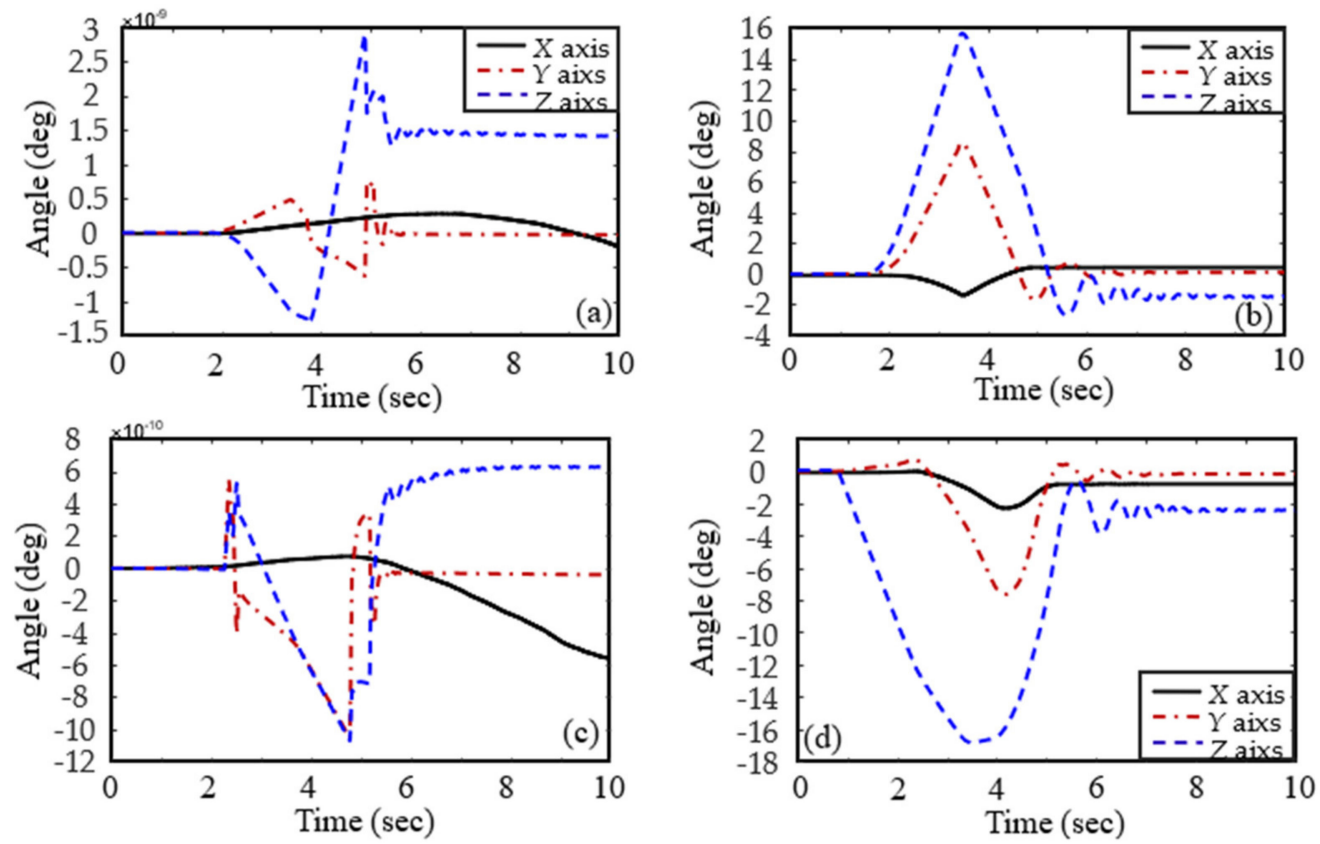

Figure 19. Time histories of angular displacements of the target $B_{8}:(\mathbf{a}) v=0.1 \mathrm{~m} / \mathrm{s},(\mathbf{b}) v=0.1 \mathrm{~m} / \mathrm{s}$, (c) $v=-0.1 \mathrm{~m} / \mathrm{s}$, and $(\mathbf{d}) v=-0.1 \mathrm{~m} / \mathrm{s}$.

(1) From Figures 10 and 14, we can observe that central impact only causes the attitude change of the robot base $B_{1}$ in the $X$ direction, but the eccentric impact could cause the attitude change in all directions.

(2) From Figures 11 and 15, we can observe that the controller designed in this paper can stabilize the motion of joint angles of the manipulator. It is observed from Figure 11a,e,f and Figure 15a,e,f that eccentric impact could cause the joint angle change of the manipulator in the Axis 1, Axis 5, and Axis 6 directions, while central impact could not.

(3) It is observed from Figures 12 and 16 that the end effecter can successfully capture the target for the four cases.

(4) From Figures 13 and 17, we can observe that central impact and eccentric impact can both lead to the deformation of the flexible links $B_{2}$ and $B_{3}$ in the $Y_{2}$ and $Y_{3}$ directions, but only the eccentric impact can lead to the deformation of $B_{2}$ and $B_{3}$ in the $Z_{2}$ and $\mathrm{Z}_{3}$ directions.

(5) As depicted in Figures 18 and 19, we can observe that eccentric impact causes obvious attitude change of $B_{8}$, meaning $B_{8}$ is tumbling, but central impact cannot. Meanwhile, it is observed that the attitude evolution trend is changed several times in eccentric impact cases, which shows that there are multiple instances of contact during capturing. Moreover, it demonstrates that the tumbling motion of the target object makes the capturing operation complicated.

(6) Figures 10-19 show the impact on the robot system caused by capturing when the target cylinder moves towards the manipulator are more significant than those when the target moves away from the manipulator.

\section{Concluding Remark}

In this paper, the process of capturing a space target using a flexible robot is studied in detail. First, the capture dynamics model is established based on the multi-body dynamics and Hertz contact theories. Then, an active compliance controller is designed to reduce the capture impact on the robot system. We found the presence of dynamic behaviors when using a flexible space robot to capture a non-cooperative target by numerical simulation. The capture impact causes attitude change of the space robot and leads to the deformation of the flexible robotic arm. Comparing different capturing scenarios, the scenario of eccentric 
impact with negative relative velocity may cause more complex dynamic behavior of the robot than others. So, to reduce the risk, that scenario should be avoided. Furthermore, when the proposed active compliance controller is considered, the capture impact on the robot can be effectively offset.

Author Contributions: Conceptualization, X.-F.L. and X.-Y.Z.; methodology, X.-F.L.; software, X.-F.L. and X.-Y.Z.; validation, X.-F.L. and X.-Y.Z.; formal analysis, X.-F.L. and X.-Y.Z.; investigation, X.-F.L. and X.-Y.Z.; resources, X.-F.L. and X.-Y.Z.; data curation, X.-F.L. and X.-Y.Z.; writing-original draft preparation, X.-F.L. and X.-Y.Z.; writing-review and editing, G.-P.C. and W.-J.C.; visualization, G.-P.C. All authors have read and agreed to the published version of the manuscript.

Funding: Natural Science Foundation of China (grant numbers 11772187, 11802174) and SAST-SJTU advanced space technology joint research fund (grant number USCAST2019-22).

Institutional Review Board Statement: Not applicable.

Informed Consent Statement: Not applicable.

Data Availability Statement: Not applicable.

Acknowledgments: This work was supported by the Natural Science Foundation of China (grant numbers 11772187, 11802174) and SAST-SJTU advanced space technology joint research fund (grant number USCAST2019-22).

Conflicts of Interest: The authors declare no conflict of interest.

\section{References}

1. Fukushima, Y.; Inaba, N.; Oda, M. Capture and berthing experiment of a massive object using ETS7 space robot. In Proceedings of the AIAA Astrodynamics Specialist Conference, Denver, CO, USA, 14-17 August 2000; pp. 635-638.

2. Friend, R.B. Orbital Express program summary and mission overview. In Proceedings of the SPIE Sensors and Systems for Space Applications II, Orlando, FL, USA, 17-18 April 2008; pp. 695801-695803.

3. Van, V.J.; Sharf, I.; Ma, O. Experimental validation of contact dynamics simulation of constrained robotic tasks. Int. J. Robot. Res. 2000, 19, 1203-1217.

4. Wee, L.B.; Walker, M.W. On the dynamics of contact between space robots and configuration control for impact minimization. IEEE Trans. Robot. Autom. 1993, 9, 581-591.

5. Cyril, X.; Jaar, G.J.; Misra, A.K. The effect of payload impact on the dynamics of a space robot. In Proceedings of the IEEE/RSJ International Conference on Intelligent Robots and Systems, Yokohama, Japan, 26-30 July 1993; pp. 2070-2075.

6. Cyril, X.; Misra, A.K.; Ingham, M.; Jaar, G.J. Postcapture dynamics of a spacecraft-manipulator-payload system. J. Guid. Control Dyn. 2000, 23, 95-100. [CrossRef]

7. Yoshida, K.; Sashida, N.; Kurazume, R.; Umetani, Y. Modeling of collision dynamics for space free-floating links with extended generalized inertia tensor. In Proceedings of the IEEE International Conference on Robotics and Automation, Nice, France, 12-14 May 1992; Volume 1, pp. 899-904.

8. Yoshida, K.; Sashida, N. Modeling of impact dynamics and impulse minimization for space robots. In Proceedings of the IEEE/RSJ International Conference on Intelligent Robots and Systems, Yokohama, Japan, 26-30 July 1993; Volume 3, pp. $2064-2069$.

9. Yoshida, K.; Mavroidis, C.; Dubowsky, S. Impact dynamics of space long reach manipulator. In Proceedings of the IEEE International Conference on Robotics and Automation, Minneapolis, MN, USA, 22-28 April 1996; pp. 1909-1916.

10. Yoshida, K.; Nakanishi, H. Impedance matching in capturing a satellite by a space robot. In Proceedings of the IEEE/RSJ International Conference on Intelligent Robots and Systems, Las Vegas, NV, USA, 27-31 October 2003; Volume 4, pp. 3059-3064.

11. Yoshida, K.; Nakanishi, H.; Ueno, H.; Inaba, N.; Nishimaki, T.; Oda, M. Dynamics, control and impedance matching for robotic capture of a non-cooperative satellite. Adv. Robot. 2004, 18, 175-198. [CrossRef]

12. Yoshida, K.; Dimitrov, D.; Nakanishi, H. On the capture of tumbling satellite by a space robot. In Proceedings of the IEEE/RSJ International Conference on Intelligent Robots and Systems, Beijing, China, 9-15 October 2006; pp. 4127-4132.

13. Shibli, M.; Aghili, F.; Su, C.-Y. Modeling of a free-flying space robot manipulator in contact with a target satellite. In Proceedings of the IEEE Conference on Control Applications, Toronto, ON, Canada, 28-31 August 2005; pp. 559-564.

14. Shibli, M.; Su, C.-Y.; Aghili, F. Adaptive inverse dynamics control of free-flying space robot contact with a target satellite: A Hubble space telescope case. In Proceedings of the IEEE Canadian Conference on Electrical and Computer Engineering, Ottawa, ON, Canada, 7-10 May 2006; pp. 1275-1278.

15. Matunaga, S.; Kanzawa, T.; Ohkami, Y. Rotational motion-damper for the capture of an uncontrolled floating satellite. Control Eng. Pract. 2001, 9, 199-205. [CrossRef] 
16. Uyama, N.; Hirano, D.; Nakanishi, H.; Nagaoka, K.; Yoshida, K. Impedance-based contact control of a free-flying space robot with respect to coefficient of restitution. In Proceedings of the IEEE/SICE International Symposium on System Integration (SII), Kyoto, Japan, 20-22 December 2011; pp. 1196-1201.

17. Uyama, N.; Nakanishi, H.; Nagaoka, K.; Yoshida, K. Impedance-based contact control of a free-flying space robot with a compliant wrist for non-cooperative satellite capture. In Proceedings of the IEEE/RSJ International Conference on Intelligent Robots and Systems, Vilamoura-Algarve, Portugal, 7-12 October 2012; pp. 4477-4482.

18. Thai, C.; Nguyen, H.; Inna, S. Capture of spinning target with space manipulator using magneto rheological damper. In Proceedings of the AIAA Guidance, Navigation, and Control Conference, Toronto, ON, Canada, 2-5 August 2010; p. 7753.

19. Xu, W.F.; Liang, B.; Li, C.; Liu, Y.; Wang, X.Q. A modelling and simulation system of space robot for capturing non-cooperative target. Math. Comp. Model. Dyn. 2009, 15, 371-393. [CrossRef]

20. Xu, W.F.; Meng, D.S.; Chen, Y.Q.; Qian, H.H.; Xu, Y.S. Dynamics modeling and analysis of a flexible-base space robot for capturing large flexible spacecraft. Multibody Syst. Dyn. 2014, 32, 357-401. [CrossRef]

21. Liu, X.-F.; Li, H.-Q.; Chen, Y.-J.; Cai, G.-P.; Wang, X. Dynamics and control of capture of a floating rigid body by a spacecraft robotic arm. Multibody Syst. Dyn. 2015, 33, 315-332. [CrossRef]

22. Yu, Z.-W.; Liu, X.-F.; Cai, G.-P. Dynamics modeling and control of a 6-DOF space robot with flexible panels for capturing a free floating target. Acta Astronaut. 2016, 128, 560-572. [CrossRef]

23. Nishida, S.; Yoshikawa, T. Space debris capture by a joint compliance controlled robot. In Proceedings of the IEEE/ASME International Conference on Advanced Intelligent Mechatronics, Kobe, Japan, 20-24 July 2003; Volume 1, pp. 496-502.

24. Nishida, S.; Yoshikawa, T. Capture and motion braking of space debris by a space robot. In Proceedings of the International Conference on Control, Automation and Systems, Seoul, Korea, 17-20 October 2007; pp. 706-711.

25. Nishida, S.-I.; Kawamoto, S.; Okawa, Y.; Terui, F.; Kitamura, S. Space debris removal system using a small satellite. Acta Astronaut. 2009, 65, 95-102. [CrossRef]

26. Nishida, S.; Kawamoto, S. Strategy for capturing of a tumbling space debris. Acta Astronaut. 2011, 68, 113-120. [CrossRef]

27. Liu, J.; Huang, Q.; Yang, T.; Deng, T. Compliant control of a space robot with multi arms for capturing large tumbling target. In Proceedings of the IEEE International Conference on Mechatronics and Automation, Takamatsu, Japan, 6-9 August 2017; pp. 1859-1864.

28. Liu, X.-F.; Cai, G.-P.; Wang, M.-M.; Chen, W.-J. Contact control for grasping a non-cooperative satellite by a space robot. Multibody Syst. Dyn. 2020, 50, 119-141. [CrossRef]

29. Liu, X.F.; Zhang, X.Y.; Chen, P.C.; Cai, G.P. Hybrid control scheme for grasping a non-cooperative tumbling satellite. IEEE Access 2020, 8, 54963-54978. [CrossRef]

30. Stolfi, A.; Gasbarri, P.; Sabatini, M. A combined impedance-PD approach for controlling a dual-arm space manipulator in the capture of a non-cooperative target. Acta Astronaut. 2017, 139, 243-253. [CrossRef]

31. Stolfi, A.; Gasbarri, P.; Sabatini, M. A parametric analysis of a controlled deployable space manipulator for capturing a noncooperative flexible satellite. Acta Astronaut. 2018, 148, 317-326. [CrossRef]

32. Zarafshan, P.; Moosavian, S. Fuzzy tuning control approach to perform cooperative object manipulation by a rigid-flexible multibody robot. Multibody Syst. Dyn. 2017, 40, 213-233. [CrossRef]

33. Zarafshan, P.; Larimi, R.; Moosavian, S.; Siciliano, B. Which impedance strategy is the most effective for cooperative object manipulation? Ind. Robot 2017, 44, 198-209. [CrossRef]

34. Liu, X.F.; Li, H.Q.; Wang, J.S.; Cai, G.P. Dynamics analysis of flexible space robot with joint friction. Aerosp. Sci. Technol. 2015, 47, 164-176. [CrossRef]

35. Johnson, K.L. Contact Mechanics; Cambridge University Press: Cambridge, UK, 1984.

36. Ericson, C. Real-Time Collision Detection; Elsevier: Amsterdam, The Netherlands, 2005. 